\title{
Aplicación de los sistemas mixtos para el refuerzo de puentes de hormigón con patologías
}

\section{Use of Composite Structures for the Strengthening of Concrete Bridges with Pathologies}

\author{
Francisco Millanes Mato ${ }^{\mathrm{a}}$, Miguel Ortega Cornejo ${ }^{\mathrm{b}}$, Ignacio Pulido Sánchez ${ }^{\mathrm{c}}$, \\ Santiago Salas Fernández-Polanco ${ }^{c}$, y Enrique Bordó Bujalance \\ ${ }^{a}$ Doctor Ingeniero de Caminos Canales y Puertos. Presidente. IDEAM, S.A. \\ ${ }^{b}$ Máster Ingeniero de Caminos Canales y Puertos. Director de Ingeniería. IDEAM, S.A. \\ ${ }^{c}$ Máster Ingeniero de Caminos, Canales y Puertos. IDEAM, S.A.
}

Recibido el 10 de diciembre de 2020; aceptado el 16 de abril de 2021

\begin{abstract}
RESUMEN
Las estructuras mixtas presentan una amplia gama de posibilidades para la reparación y refuerzo de puentes de hormigón. El uso de este tipo de estructuras supone una serie de ventajas respecto a otros métodos como son en muchos casos la flexibilidad, polivalencia, alta capacidad resistente en proporción al peso, y facilidad de ejecución. Aspectos importantes a tener en cuenta son el montaje de uniones y el control de tolerancias geométricas, así como la conexión entre la estructura metálica y el puente de hormigón existente. En el artículo se citan diferentes ejemplos y detalles utilizados por diferentes ingenierías para solucionar tanto nuevas necesidades funcionales como resistentes, desarrollando con un mayor grado de detalle la solución implementada en el viaducto sobre el río Duero en la A-66, en Zamora (España). Esta estructura, formada por un cajón de hormigón pretensado que adolecía de patologías en el hormigón, fue reforzada de manera integral mediante el montaje de sendas vigas metálicas adosadas al cajón existente, dando lugar como nueva estructura resistente a un tablero mixto..
\end{abstract}

PALABRAS CLAVE: Estructura mixta, refuerzo, conexión, reparación de estructuras.

(C) 2021 Asociación Española de Ingeniería Estructural (ACHE). Publicado por Cinter Divulgación Técnica S.L. Todos los derechos reservados.

\section{ABSTRACT}

Composite structures have a wide range of possibilities for reparation and strengthening of concrete bridges. The use of this type of structures provides several advantages compared to other methods such as flexibility, polyvalency, high resistance capacity in relation to the weight and ease of execution. Important aspects that must be considered are the joints assembly and the control of geometric tolerances, as well as the connection between the steel structure and the existing concrete bridge.

The article shows different examples and details designed by different engineering firms to solve both new functional and resistant needs, developing in greater detail the solution implemented in the viaduct on the Douro River on the A-66, in Zamora (Spain). This structure, consisting of a concrete box girder bridge that suffered several structural pathologies, was entirely reinforced by the assembly of a steel structure on the exterior side of the deck. The steel structure connects with the existing bridge resulting a composite structure with double composite action.

KEYWORDS: Composite structure, strengthening, connection, structural repair.

〔C 2021 Asociación Española de Ingeniería Estructural (ACHE). Published by Cinter Divulgación Técnica S.L. All rights reserved.

* Persona de contacto / Corresponding author:

Correo-e / email: ignacio.pulido@ideam.es (Ignacio Pulido) 
1.

\section{INTRODUCCIÓN}

El artículo describe las posibilidades que ofrece el uso de soluciones metálicas y mixtas en la reparación y refuerzo de estructuras de hormigón afectadas por patologías. Si bien son conocidas las prestaciones de las estructuras mixtas diseñadas para obras de nueva ejecución, quizás es menos habitual su consideración como herramienta en obras de rehabilitación. Es intención de los autores llamar la atención sobre las posibilidades que ofrecen estas soluciones.

Junto a la exposición de la problemática de dichos refuerzos, y sus ventajas e inconvenientes, se describe un caso reciente de aplicación a una estructura de la que se realizó rehabilitación integral, el puente paso de la A-66 sobre el río Duero, en la provincia de Zamora ${ }^{1}$.

\section{2.}

\section{USO DE LA TECNOLOGÍA MIXTA PARA LA REPARACIÓN Y REFUERZO DE PUENTES DE HORMIGÓN}

Las soluciones basadas en el uso del metal como material de refuerzo permiten aprovechar las conocidas ventajas inherentes a esta tecnología, tanto en el caso de un diseño puramente metálico, como cuando se hace trabajar a los elementos como secciones mixtas.

Uno de los principales aspectos que caracteriza el empleo de la tecnología mixta para la reparación de estructuras de hormigón es su amplia flexibilidad y polivalencia. El uso del acero, generalmente dando lugar a piezas de relativamente poco peso y montaje por segmentos, hace posible que el refuerzo metálico se pueda adaptar con facilidad al elemento a reforzar, a la vez que, dadas sus superiores prestaciones mecánicas, permite ejecutar una amplia gama tipológica de reparaciones o soluciones: refuerzos a cortante en almas, aumento de la capacidad a flexión, refuerzos locales para puenteo de cargas, etc.

Su uso no solo permite reparar los daños en obras con patologías sino que, además, habilita una amplia gama de actuaciones complementarias, entre las que se puede citar: aumentar la capacidad resistente de puentes de hormigón (tengan o no patologías) que por motivos de explotación así lo requieran; aumentar las luces de estructuras por medio de supresión o modificación de soportes; incrementar el ancho de plataformas de tableros; y un largo etc.

En lo que se refiere a los aspectos constructivos de la solución, el empleo de estructuras mixtas suele ser una opción que, habitualmente, supone unos montajes limpios, sencillos y rápidos.

En cuanto a la estética de las soluciones mixtas en el refuerzo de estructuras, la citada flexibilidad formal permite introducir cambios estéticos menores en las obras existentes, ya que se pueden ceñir con facilidad a la geometría existente (si esta no es excesivamente compleja) y el uso del acero permite introducir refuerzos de dimensiones reducidas, siendo por

1 Reparación y refuerzo del que IDEAM ha sido proyectista y asistencia técnica a la propiedad. tanto muy poco intrusivas. Además, el acero puede llevar tratamientos de pintura que suelen permitir conservar la concepción estética inicial del proyecto o, por otra parte, introducir contrastes de materiales agradables en el caso del acero corten.

Otro aspecto fundamental en cualquier obra, ya sea de nueva construcción o reparación, es el respeto y la integración medio ambiental. En este sentido las estructuras mixtas suponen una buena alternativa, con un impacto medio ambiental reducido, entendiendo por esto la sencillez de montaje que da lugar a operaciones con menor maquinaria, menores afecciones a los elementos existentes en la sombra del puente y posibles menores vertidos al entorno. El menor impacto ambiental puede ser un punto fundamental para la elección de este tipo de estructuras en el caso de refuerzos.

En el lado de los inconvenientes a la hora de considerar su uso, podemos citar los casos de puentes con geometría de cierta complejidad (puentes curvos, de canto variable, con los paramentos de hormigón no perfectamente planos, etc.). La dificultad radica tanto en la correcta definición de la geometría (a pesar de las potentes herramientas de toma de datos de la obra existente que existen ahora), como en la ejecución en Taller (con imprescindibles montajes en blanco), y especialmente en el ensamblaje en obra, donde la presencia de tolerancias de montaje estrictas puede hacer preferibles otras soluciones.

En algunos casos, la adaptación de una estructura metálica a una estructura de hormigón puede requerir de medios auxiliares especiales o diseñados ad hoc para la solución propuesta con el fin de poner desplazar, posicionar y ajustar la estructura metálica, lo que puede encarecer la construcción.

Otro punto de dificultad a considerar, del que se trata más adelante, es la necesidad de conectar la nueva estructura metálica al puente de hormigón para conseguir que la transmisión de esfuerzos o para que ambas trabajen como una estructura mixta. La necesidad de conectar metal y hormigón puede dar lugar a complejas y laboriosas operaciones en obra, como hidrodemoliciones, taladros, corte de piezas, etc.

Por último, si bien la fabricación en taller lleva asociada un preciso control de calidad y permite ejecutar soldaduras de gran calidad por las óptimas condiciones de ejecución, el ensamblaje en obra de las diferentes piezas puede requerir soldaduras complejas o que precisen ser ejecutadas en condiciones más delicadas. Estas pueden encarecer la solución por los menores rendimientos y las necesidades de control de las soldaduras.

No es objeto del presente artículo la exposición y valoración de otras posibles técnicas de refuerzo, como pudieran ser los recrecidos con hormigón estructural, los sistemas de pretensado exterior, el uso de laminados de fibra de carbono o cualquier otro sistema de refuerzo posible, sino de exponer la versatilidad y bondades técnicas que ofrece la estructura metálica en su utilización de refuerzos de estructuras.

\section{3. \\ EJEMPLOS DE APLICACIONES MÁS COMUNES}

Las estructuras mixtas cuentan con numerosas posibilidades en las aplicaciones de reparación de puentes de hormigón. Se indican a continuación los más habituales. 

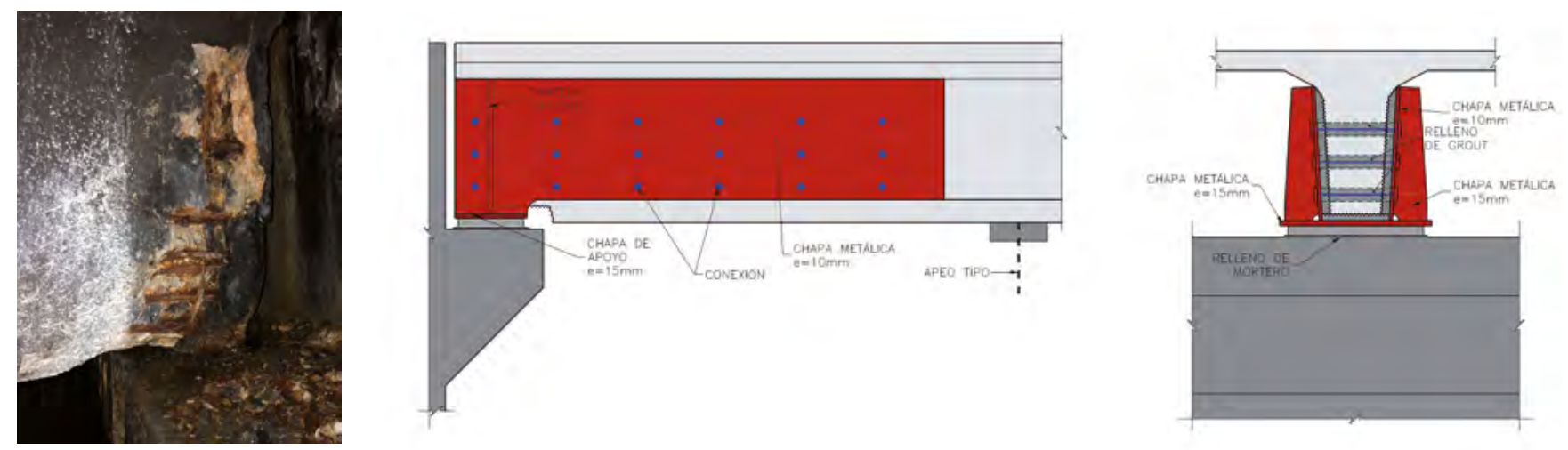

Figura 1. Deterioro culata de viga de hormigón pretensado y refuerzo de las mismas.

\subsection{Refuerzos a flexión y cortante en tableros}

En primer lugar, los puentes de hormigón dañados o a los que se aumente la carga de explotación pueden requerir refuerzos a flexión y/o cortante. Estas operaciones son muy comunes.

En el caso, p.ej., del diseño de un refuerzo a flexión positiva, la solución es sencilla, y en la mayoría de los casos puede consistir en disponer platabandas metálicas en la cara inferior del puente de hormigón, bien sean vigas o losas. Para el trabajo conjunto como sección mixta es necesario una adecuada conexión de ambos elementos.

Cuando se presente algún tipo de patología que reduzca la capacidad a cortante del puente, las estructuras mixtas permiten una limpia solución sin más que adosar almas metálicas convenientemente conectadas a las vigas de hormigón o a las almas de vigas artesas, cajones, etc. que presenten falta de capacidad o armaduras a cortante. Lógicamente, estos esquemas de refuerzo han de cumplir con la premisa de garantizar el correspondiente esquema estructural resistente en el que se han de materializar los nudos de la celosía de cortante. Dado que estos refuerzos se disponen fundamentalmente en las zonas de apoyo, una de las dificultades que suele presentarse es la transmisión de esfuerzos de la nueva estructura a la subestructura. Suele ser necesario realizar operaciones de transferencia de carga y cambio de los puntos de apoyo, que en algunos casos requiere actuaciones de ampliación de pilas y estribos por necesidades de espacio.

Un caso común relacionado con lo anterior es el de reparación de las patologías en culatas de viga. Estos elementos suelen ser susceptibles de sufrir daños estructurales como consecuencia del agua que se filtra a través de las juntas de dilatación o bien derivado del efecto de la concentración de tensiones por deficientes condiciones de apoyo o errores de diseño. Lo anterior da lugar a la degradación del hormigón y las armaduras asociadas a ese detalle, lo que puede provocar que salte el recubrimiento o en algunos casos volúmenes mayores de hormigón, pudiendo llegar a comprometer el apoyo de las vigas (figura 1). En estas situaciones una buena solución puede consistir en disponer unas almas metálicas adosadas a las vigas existentes y conectadas a las mismas. La disposición de este tipo de refuerzos suele requerir, como se ha indicado, realizar una transferencia provisional de carga de la viga para poder cambiar el punto de apoyo del tablero.
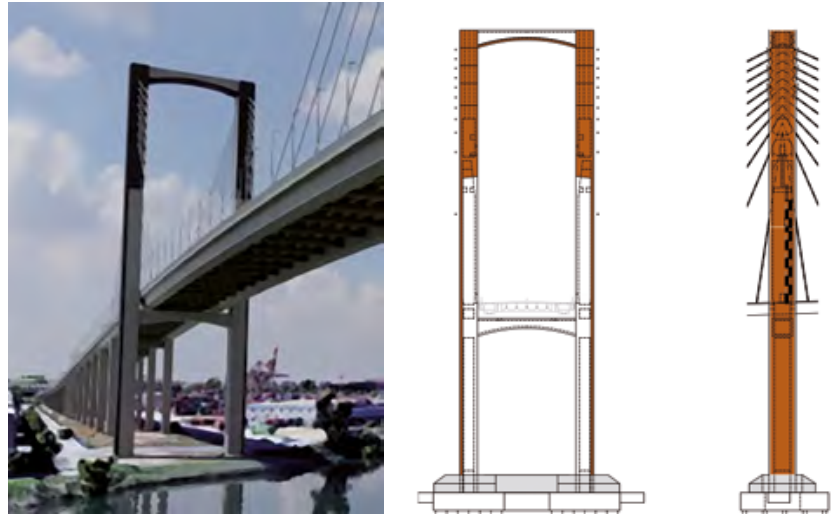

Figura 2. Vista general del pilono existente.

Cuando de lo que se trata es de aumentar la capacidad resistente conjunta de un tablero de vigas o cajón más losa, tanto a flexión como a cortante, es posible conectar a las vigas o cajón existentes nuevas vigas metálicas, de forma que se aproveche la losa de compresión como elemento resistente. Un ejemplo de esta solución es el puente del Duero en Zamora, descrito en detalle más adelante.

\subsection{Refuerzos y aumento de sección en pilas}

El empleo de estas estructuras también es aplicable en la reparación o refuerzo de pilas. Como ejemplo de lo anterior, merece la pena citar el nuevo proyecto de sustitución de tirantes del puente del Centenario en Sevilla ${ }^{2}$, donde el uso de estructuras mixtas ha permitido ampliar los fustes de los pilonos, con el doble objetivo de reforzarlos y desplazar hacia el exterior la posición del futuro nuevo plano de tirantes.

Los pilonos del puente del Centenario están constituidos por una estructura mixta formada por un cajón de hormigón al que se conecta un recubrimiento metálico colaborante en la cara exterior de los fustes (figura 2).

La sustitución de tirantes contempla desplazar los planos de tirantes hacia el exterior para dotar a la plataforma de un mayor ancho y posibilitar la sustitución de tirantes. Para poder

2 Proyecto original desarrollado por IDEAM en los años 80. Proyecto de sustitución de tirantes desarrollado por la UTE IDEAM-FHECOR. 

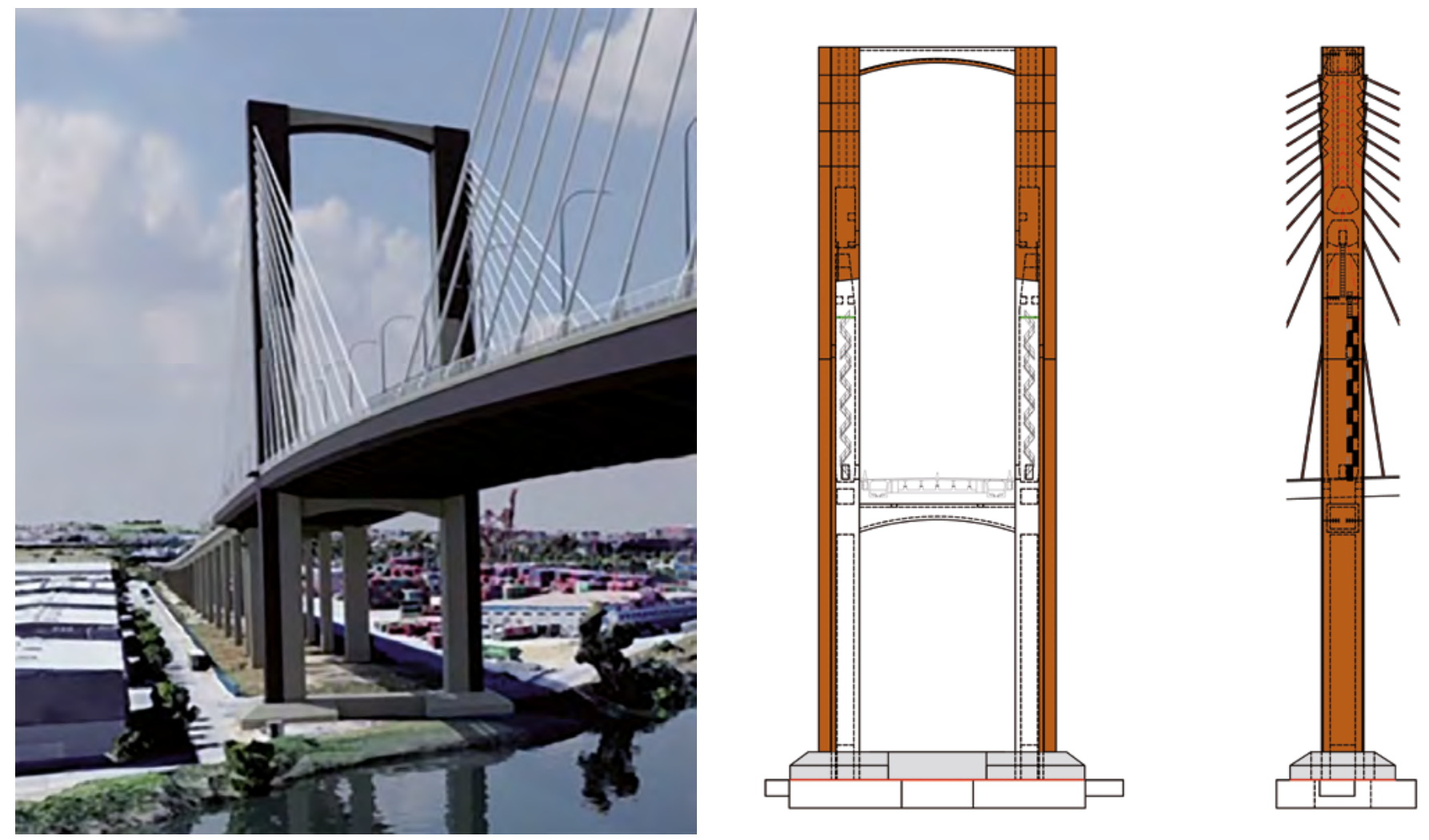

Figura 3. Vista general del pilono recrecido.

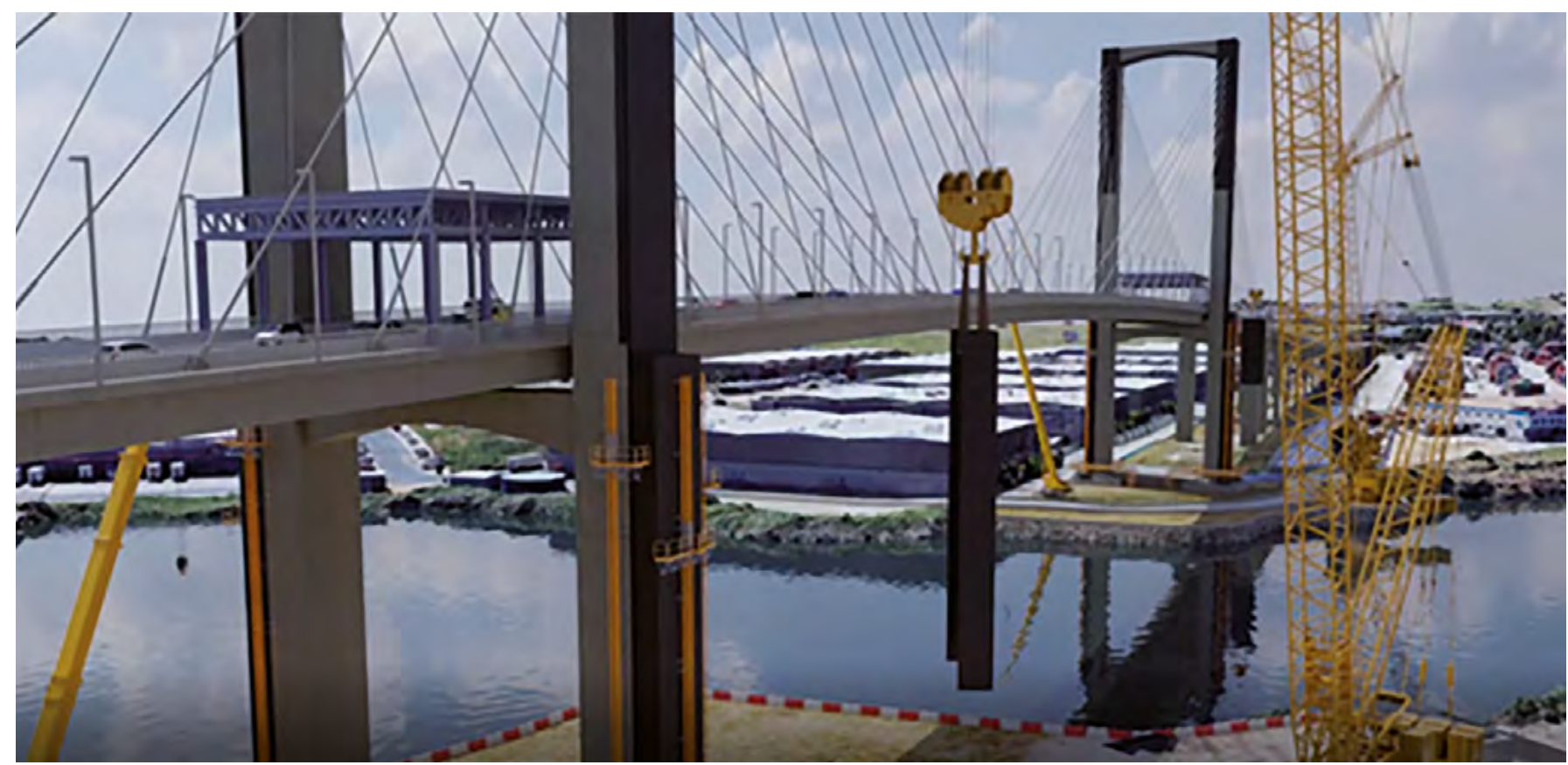

Figura 4. Recreación del montaje del recrecido de los pilonos.

trasladar los tirantes de posición resulta necesario ejecutar un recrecido de los fustes actuales, así como ejecutar el refuerzo de estos. El recrecido consiste en adosar un cajón metálico a la chapa lateral del pilono actual. Dicho cajón se vincula a la sección existente mediante una soldadura continua en toda la altura y a su vez mediante una serie de diafragmas conectados a la sección de hormigón por medio de barras de pretensado. La sección ampliada es mixta desde la base del fuste hasta una cierta cota pasado el travesaño inferior, donde pasa a estar for- mada por un cajón metálico hueco (figuras 3, 4 y 5).

Otro ejemplo de actuaciones en pilas de puentes atirantados se encuentra en la ampliación del puente atirantado de Rande $^{3}$, donde para poder disponer dos nuevos planos de tirantes exteriores a los existentes se amplió la cabeza del pilono de hormigón armado mediante un cajón metálico (figura 6). En dicho cajón se materializó el anclaje de los nuevos tirantes que permitieron sustentar dos nuevos tableros mix-

3 Proyecto realizado por MC-2 junto con Manuel Juliá Vilardell. 

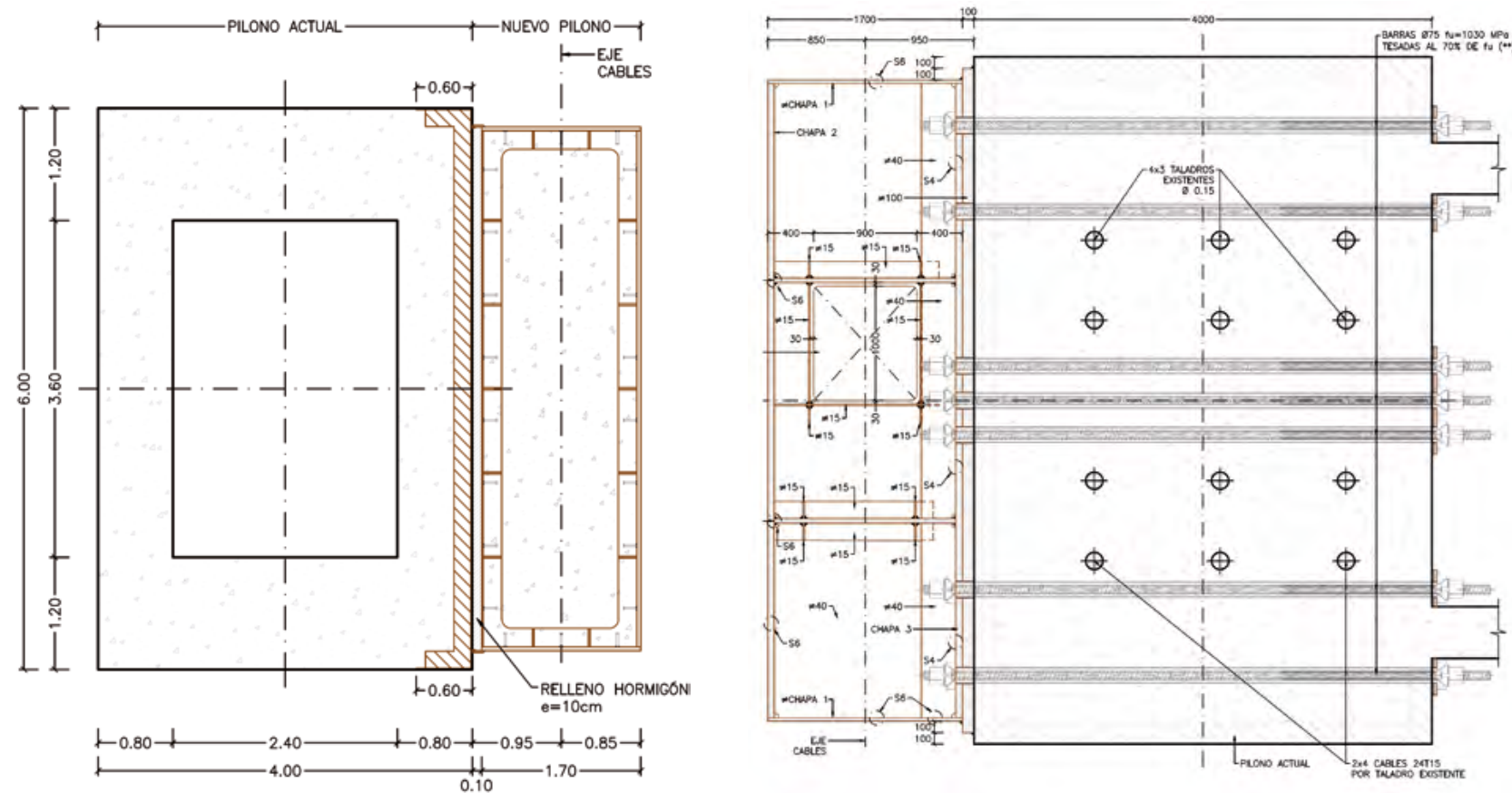

Figura 5. Sección transversal del pilono recrecido en el lateral exterior mediante una estructura mixta y detalle de conexión del cajón metálico al pilono mediante barras de pretensado.

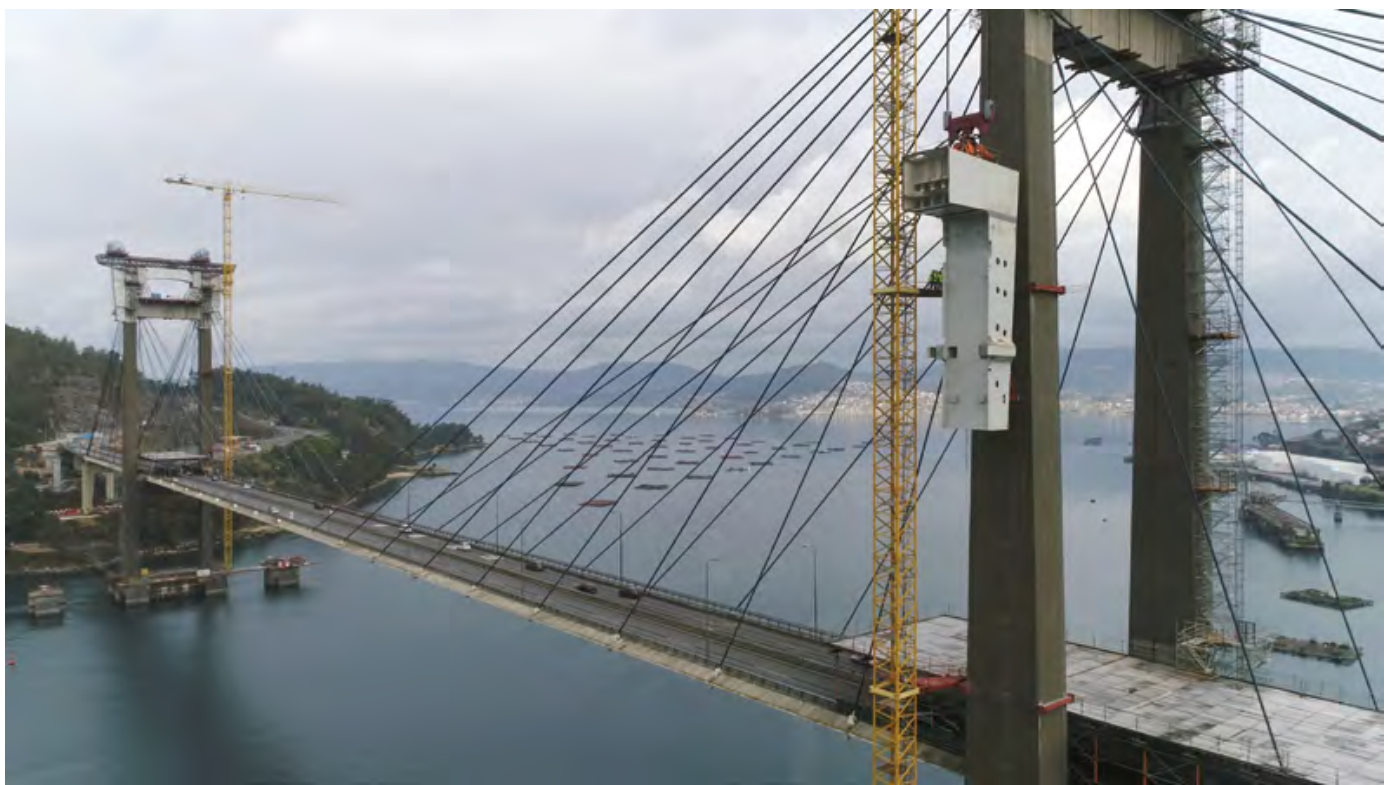

Figura 6. Montaje de la ampliación de la cabeza de los pilonos del puente de Rande (Fuente Ministerio de Transportes, Movilidad y Agenda Urbana).

tos exteriores, pudiendo dotar así a la carretera AP-9 de dos nuevos carriles.

\subsection{Cambios en la ubicación de pilas}

Junto a las reparaciones locales y refuerzos integrales mencionados, el uso de los sistemas mixtos permite realizar modificaciones estructurales no asociadas a patologías como pueden ser ampliaciones de tableros o pilas, aumento de luces y eliminación de soportes.
Un ejemplo de ello son las obras de aumento de luz en numerosos pasos de autovía en nuestro país. Puede citarse la solución ${ }^{4}$ para incrementar la luz de los pasos superiores de hormigón postesados sobre la autopista A-7 (tramo Barcelona - La Junquera) y permitir de esta manera ensanchar a 6 carriles dicha carretera (figura 7). El procedimiento consistió en adosar a las losas de hormigón existentes sendas vigas metálicas en los laterales de las mismas que apoyan en los nuevos ejes de pila de la estructura. La viga metálica tiene una doble función: por

4 Solución estructural desarrollada por Julio Martínez Calzón [1] 

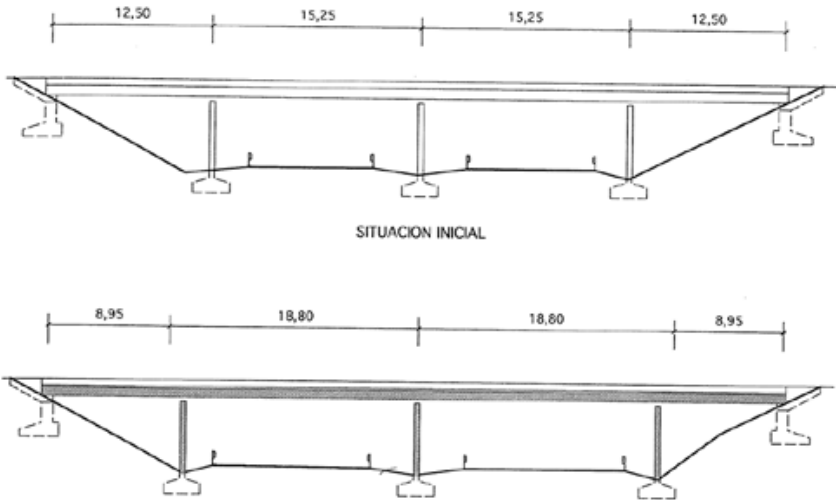

SITUACION FINAL

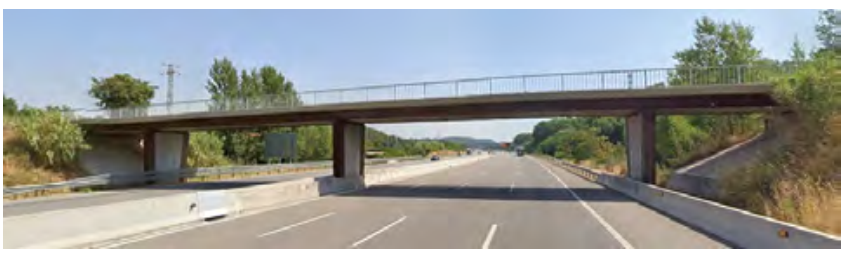

Figura 7. Ampliación de luces en pasos superiores.

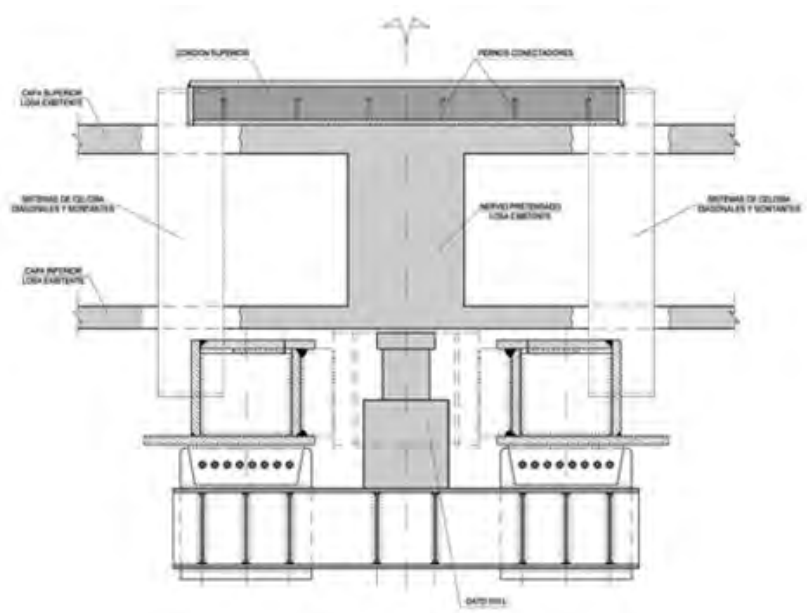

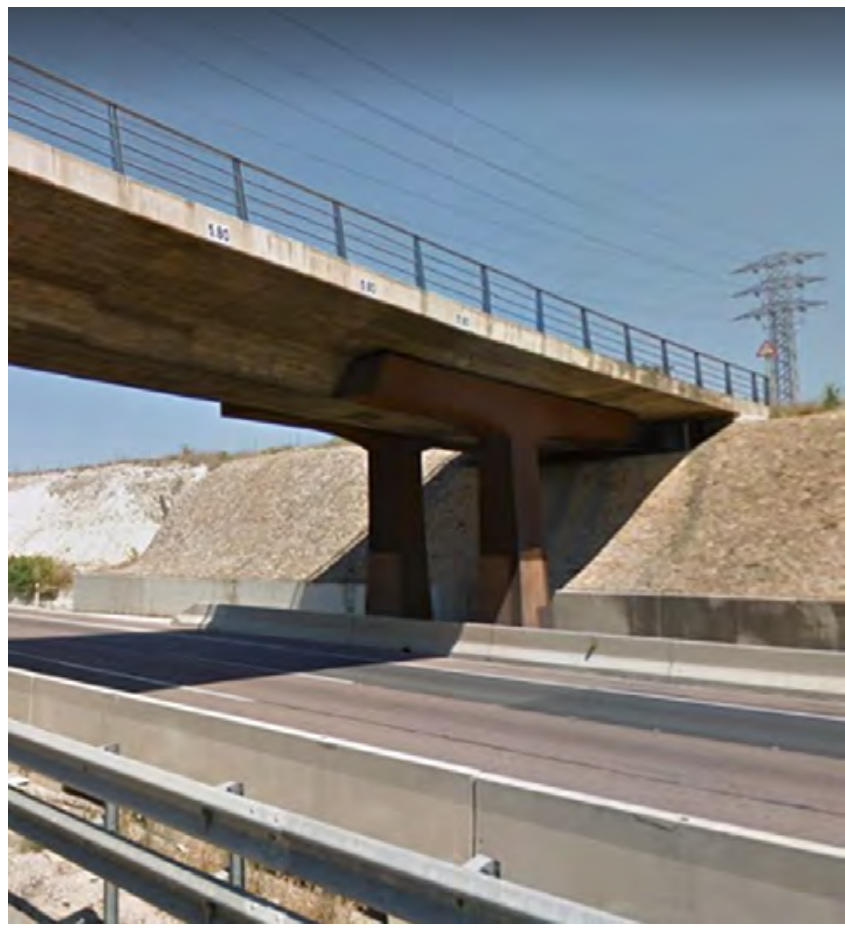

Figura 8. Ampliación de luces en paso superior mediante pescante metálico.

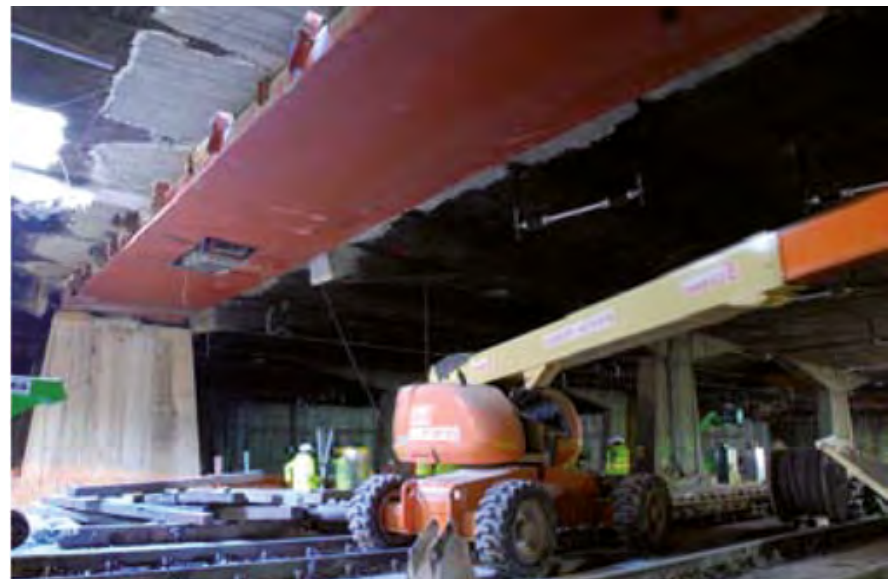

Figura 9. Sección transversal tipo par el corte de soportes en la estación de Sants. Vista del dintel mixto tras el corte del soporte (Fuente: IV Congreso ACHE [3]).

un lado permite recoger la reacción del tablero de hormigón original y trasladarla al nuevo eje de apoyo sin modificar las leyes de esfuerzo ni deformada de la estructura existente y, por otro lado, colaborar en la resistencia de las sobrecargas de uso una vez que ambas estructuras se vinculan. La conexión de ambos elementos se lleva a cabo mediante un cosido con barras de pretensado en las zonas próximas al eje de apoyo original. Con esta metodología se pueden conseguir incrementos de luz de entre el 20 y $35 \%$ de la luz original. [2].

Una variante de esta aplicación, con el mismo concepto estructural, consiste en sustituir las vigas metálicas longitudinales por unos pescantes metálicos que recojan la reacción del tablero de hormigón en la sección de apoyo original como puede verse en la figura 8 [2].

Relacionado con lo anterior se encontrarían los procedimientos para la eliminación de pilares que son herramienta habitual en obras de edificación. Citamos como ejemplo los dinteles ejecutados para el corte de soportes en la estación de Sants de Barcelona ${ }^{5}$. Para evitar demoler la cobertura de la estación, se buscó una solución que permitía entrelazarse con la losa de cubierta. Dicho sistema consistía en un dintel formado por una celosía metálica cuyo cordón superior está formado por un cajón mixto relleno de hormigón y los cordones inferiores por dos cajones metálicos (figura 9).

\subsection{Conexión con la estructura existente}

Cuando hablamos de reparación de puentes de hormigón usando los sistemas mixtos citados, uno de los principales aspectos a tener en cuenta suele ser la conexión, imprescindible

5 Proyecto de MC-2. [3]. 

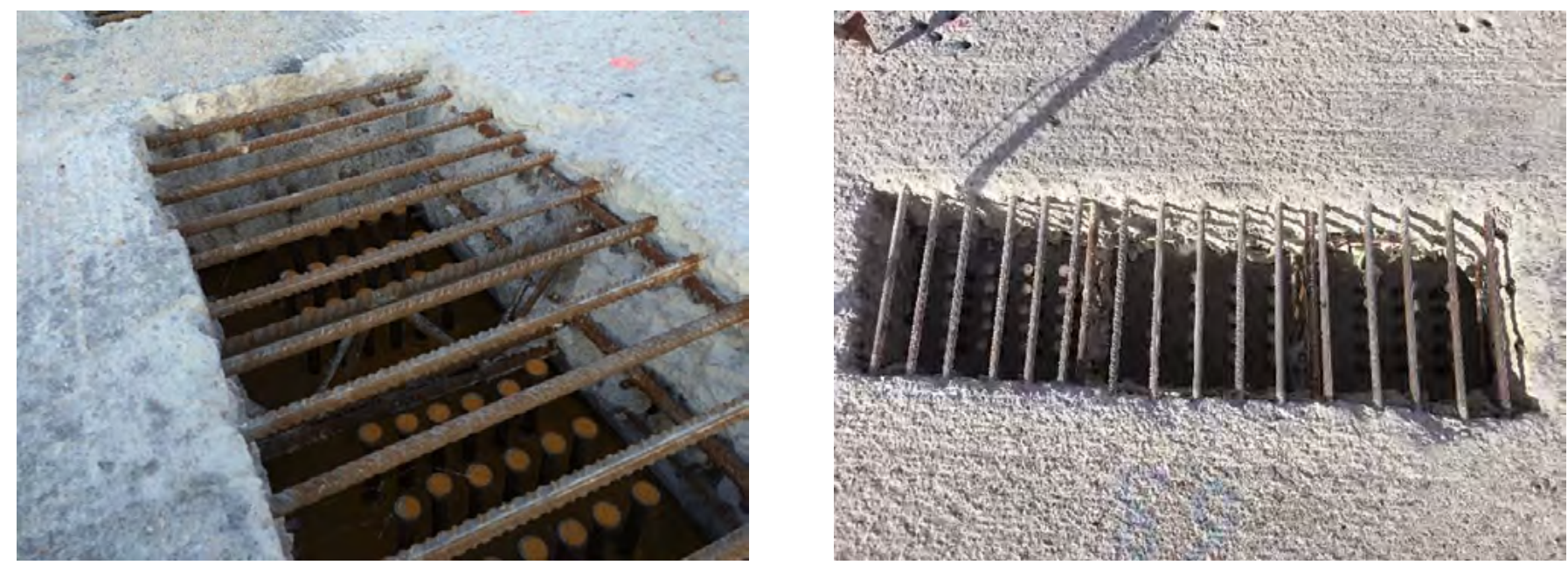

Figura 10. Hidrodemolición de una losa de hormigón para albergar los pernos conectadores de la futura sección mixta.
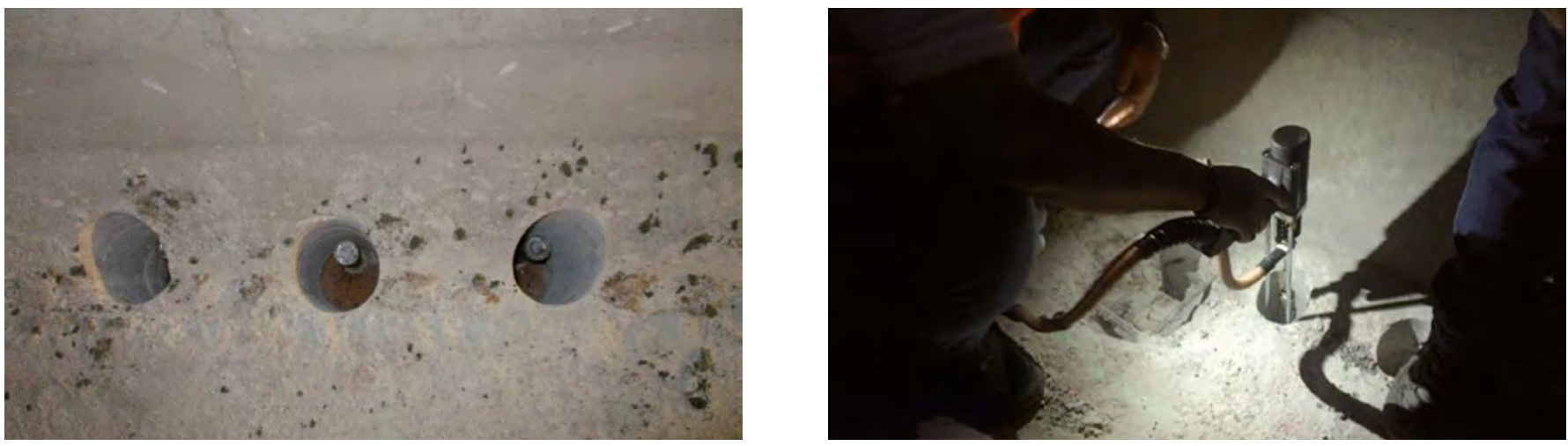

Figura 11. Soldeo de pernos en el interior de un cajón de hormigón.

para el trabajo conjunto de los materiales y para la introducción de cargas en el refuerzo. Es evidente que es un problema más complicado que en elementos de obra nueva, en los cuales pueden preverse a priori tanto el tipo de conexión como los armados, o la secuencia de ejecución más adecuada.

A la hora de definir la unión del refuerzo metálico a la pieza de hormigón, el proyectista debe preguntarse si se va a disponer una conexión localizada o una conexión distribuida. Esto dependerá de la forma de transmisión de esfuerzos y el tipo de refuerzo que se esté diseñando, y repercutirá significativamente en la configuración del refuerzo.

Si se trata de un caso, p. ej., en el que lo que se busca es transmitir los esfuerzos del tablero de hormigón a un elemento metálico en un punto concreto, como en la ampliación de luces en pasos superiores comentada, habrá que recurrir a una conexión localizada en el punto de interés.

La conexión distribuida, mucho más empleada en estructuras mixtas de diseño convencional, puede emplearse en situaciones en las que la reparación consiste en aprovechar una losa de hormigón existente incorporando vigas metálicas para el trabajo conjunto como sección mixta, o también en refuerzos a flexión con chapas largas que lo habiliten por espacio.

En todo caso, el mero hecho de realizar la conexión del metal a la obra de hormigón no asegura el correcto comportamiento como estructura mixta. Uno de los aspectos clave que hay que verificar es que la estructura existente es capaz de transmitir los esfuerzos localizados requeridos, así como que el armado existente en la sección de hormigón es suficiente para asegurar dicha transferencia (y en caso de no ser así, se deberá reforzar dicho armado, cosa no siempre posible).

En cuanto a las soluciones de conexión disponibles, hay gran variabilidad en función del tipo de unión que se busque:

- En los casos en los que se busca una conexión pura por rasante, los elementos habitualmente empleados suelen ser pernos conectadores, tacos de conexión o topes metálicos distribuidos. La disposición de este tipo de elementos obliga a resolver el problema de como dejar embebidos dichos elementos en el hormigón existente.

Una de las soluciones a la que es frecuente recurrir es la hidrodemolición parcial de la losa para generar espacio para la conexión y su posterior hormigonado (figura 10). Este método presenta varios inconvenientes o dificultades, como por ejemplo la necesidad de demoler la losa por bataches para garantizar la integridad estructural de la misma durante la actuación. Esto implica, habitualmente, la necesidad de soldar los elementos de conexión en obra, ya que no suele ser posible montar una estructura con los elementos de conexión soldados si previamente no se ha demolido la losa en la zona que forma parte de la cabeza de compresión de la futura sección.

Por otro lado, para la disposición de este tipo de conectadores existe la posibilidad de ejecutar taladros independientes en el tablero de hormigón que permitan albergar cada uno de los elementos de conexión (figura 11). Esta solución también 

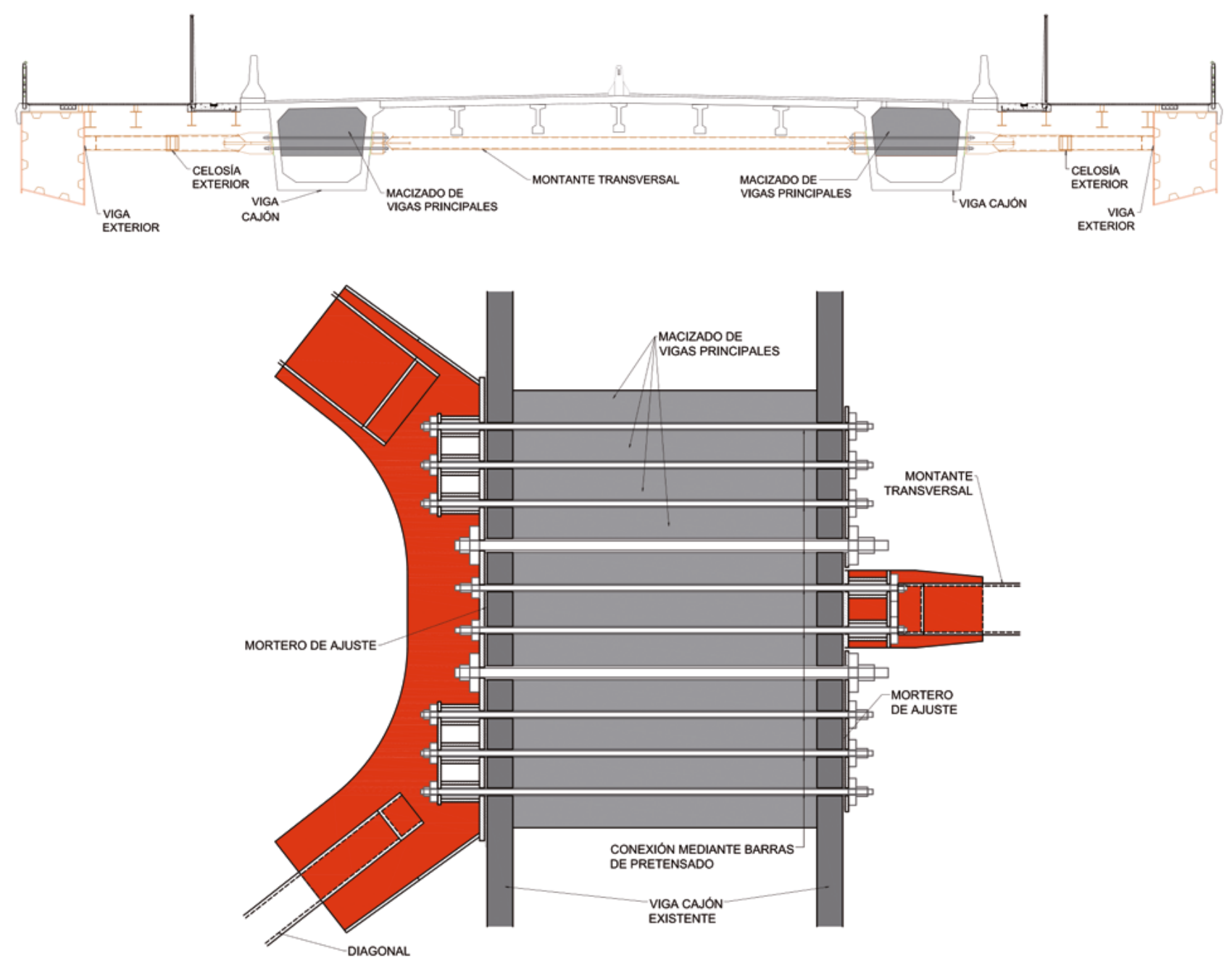

Figura 12. Arriba, sección transversal tipo del puente del Centenario tras la sustitución de tirantes. Abajo, detalle en planta de la conexión celosía-cajón de hormigón prefabricado existente resuelta mediante barras pretensadas de los montantes transversales y celosía exterior.

lleva asociada complejidades para la obra. En el caso de que se quiera montar la estructura metálica con los pernos ya soldados será necesario realizar un levantamiento topográfico muy preciso de la posición de los taladros para que, posteriormente, en taller puedan soldar los pernos en la posición exacta. Posteriormente habrá que rellenar los taladros ejecutados con un grout por lo que, si no resultan accesibles, como es el caso de los taladros no pasantes, habrá que recurrir a operaciones de inyección. Si, por ejemplo, se hacen taladros pasantes que permiten tanto soldar pernos in situ evitando las complejas tareas de replanteo como el fácil relleno de los taladros, debe tenerse en cuenta que habrá que buscar métodos que permitan el soldeo del elemento en el espacio disponible.

- Los esfuerzos de conexión pueden transmitirse por rozamiento entre el hormigón y el acero a través de uniones con tornillos o barras de pretensado como se ha indicado anteriormente para el caso de las pilas del Puente del Centenario, o como se ha usado en dicha obra para la conexión de las barras de la celosía exterior. Estas son perfiles en sección cajón cuyos esfuerzos de tracción o compresión se cosen por medio de barras pretensadas a los cajones del tablero existente, ver (figura 12).
Debe cuidarse en el diseño la zona de anclaje de barras, y asegurar que se cuenta con un coeficiente de rozamiento suficiente. El diseño frente a durabilidad de estos elementos debe ser cuidadoso, y debe asegurar que no se introducen movimientos que induzcan flexiones parásitas en las barras. En el caso de tratarse de una unión a tracción, un pretensado suficiente mantiene la interfaz comprimida de manera permanente, resultando en una buena solución en la mayoría de los casos.

- Cuando se diseñan uniones a base de topes (figura 13) o tacos de conexión, estamos hablando de un caso de transmisión directa de carga en un área localizada. Son aplicables comentarios ya realizados sobre la verificación de la zona local ante la carga puntual. En el diseño se debe tener en cuenta la posibilidad de que la carga sea reversible, ya que la transmisión directa por contacto es unidireccional. Pueden dar lugar a piezas de metal de dimensiones importantes que requieran de un montaje complicado.

- Otro ejemplo de conexión puede ser la realizada por medio de barras corrugadas soldadas a platabandas y embebidas en una sección de hormigón, o directamente ancladas con taladros a la obra existente (figura 14). 

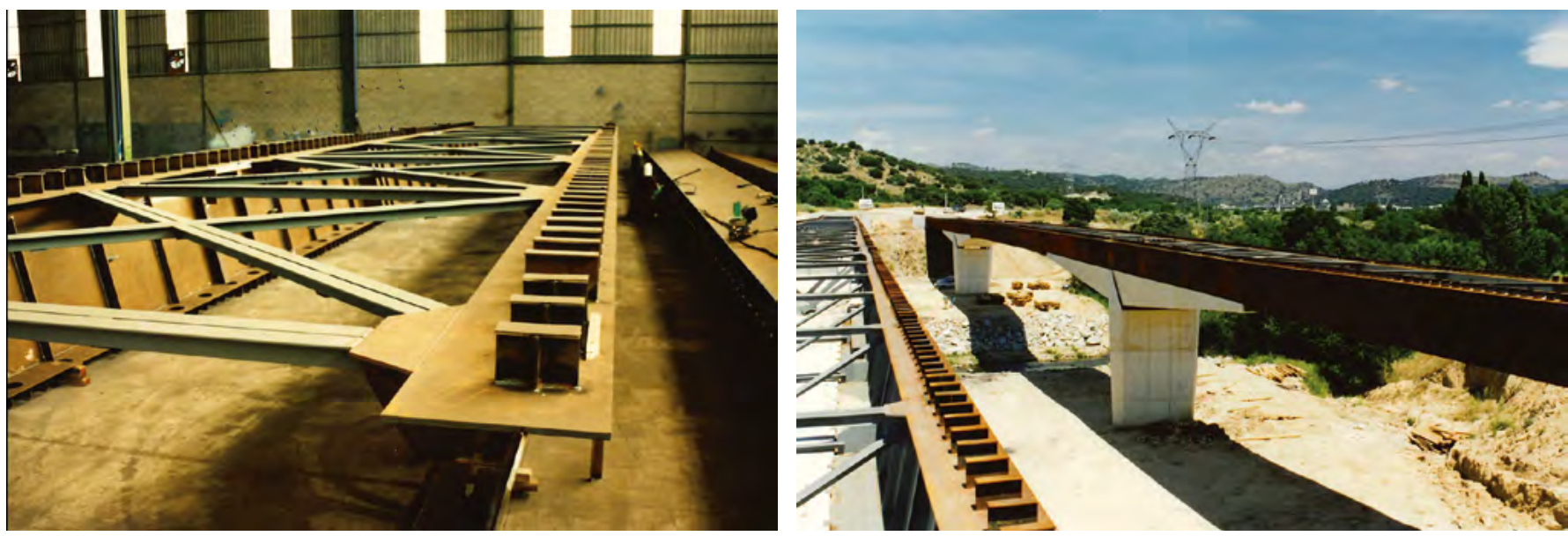

Figura 13. Topes metálicos de conexión del viaducto mixto de Retamar. ${ }^{6}$

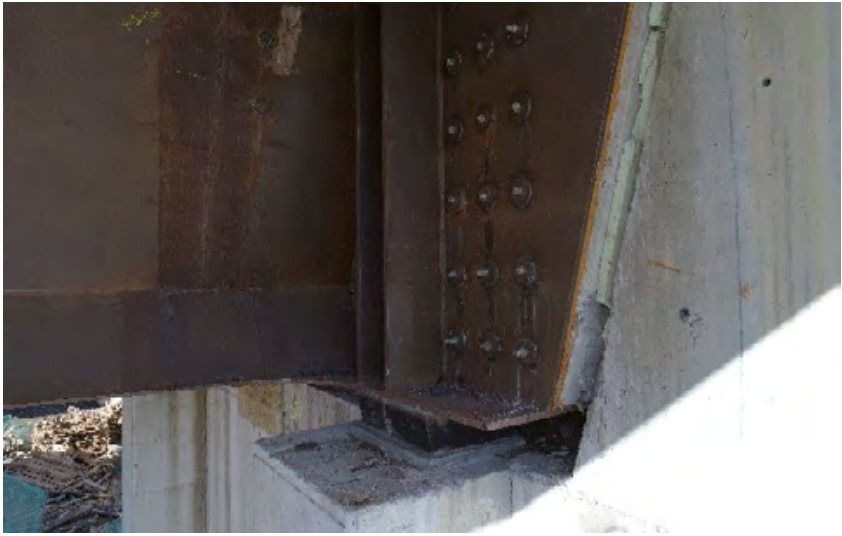

Figura 14. Conexión mediante varillas roscadas ancladas en el hormigón mediante taladros.

4.

\section{CASO PRÁCTICO: REFUERZO INTEGRAL DEL VIADUCTO SOBRE EL RÍO DUERO EN LA A-66}

Se expone a continuación un ejemplo reciente de rehabilitación y refuerzo de un puente de hormigón, donde se muestra cómo la utilización de la mayoría de las herramientas metálicas o mixtas descritas da lugar a una solución estructuralmente adecuada, y fácilmente ejecutable.

\subsection{Descripción de la estructura}

El paso de la A-66 sobre el río Duero (figuras 15 y 16), en la provincia de Zamora, se realiza por medio de dos estructuras gemelas de 277,00 m de longitud y 11,70 m de ancho de tablero, cada una de las cuales da servicio a una de las calzadas de la autovía. En planta el trazado es ligeramente curvo con radio constante. Cada una de las estructuras tiene seis vanos con 5 pilas intermedias. Las luces son de 34,50 m+36,00 m +49,50 m $+72,00 \mathrm{~m}+49,50 \mathrm{~m}+34,50 \mathrm{~m}$.

La estructura consta de cinco pilas intermedias. Las pilas P1, P2 y P5 son de hormigón armado, de fuste único de sección transversal rectangular, y ejecutadas in situ. Las pilas P3 y P4, adyacentes al vano principal, presentan una configuración es-

6 Proyectado por IDEAM. pecífica, y constan de un plinto in situ, sobre el que se apoyan, mediante dos apoyos de neopreno, dos puntales prefabricados inclinados que conectan monolíticamente con el tablero formando un pórtico de célula triangular.

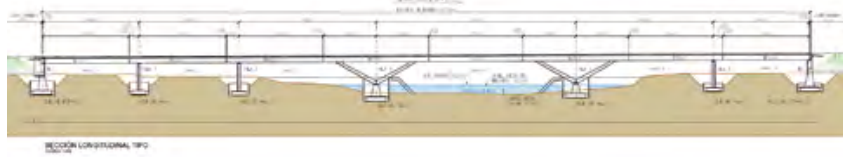

Figura 15. Alzado de la estructura.

El tablero está formado por vigas cajón prefabricadas postesadas de hormigón de 1,80 m de canto, prelosas y una losa superior de hormigón armado de $0,30 \mathrm{~m}$ de canto total, que disminuye linealmente hasta $0,20 \mathrm{~m}$, en los extremos de los voladizos. En cuanto a las vigas prefabricadas, el puente está constituido por 8 vigas, una por cada vano del puente. Las juntas entre los elementos prefabricados se disponen a 1/5 aproximadamente de la luz de cada vano.

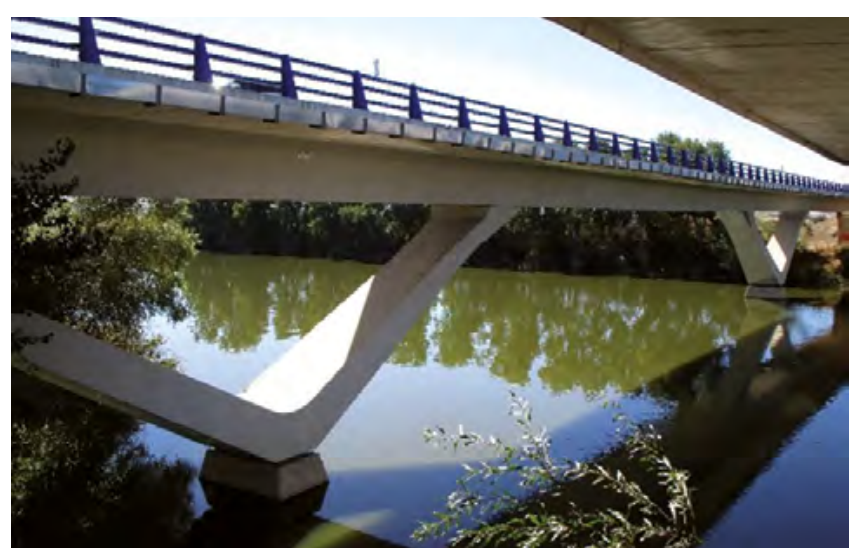

Figura 16. Vista general de la estructura en su estado original.

\subsection{Descripción general de la problemática existente y justi- ficación de la solución mixta}

La estructura sobre el río Duero presentaba una serie de daños generalizados que afectaban a su seguridad estructural, por lo que se consideró necesario disponer un mecanismo resistente 


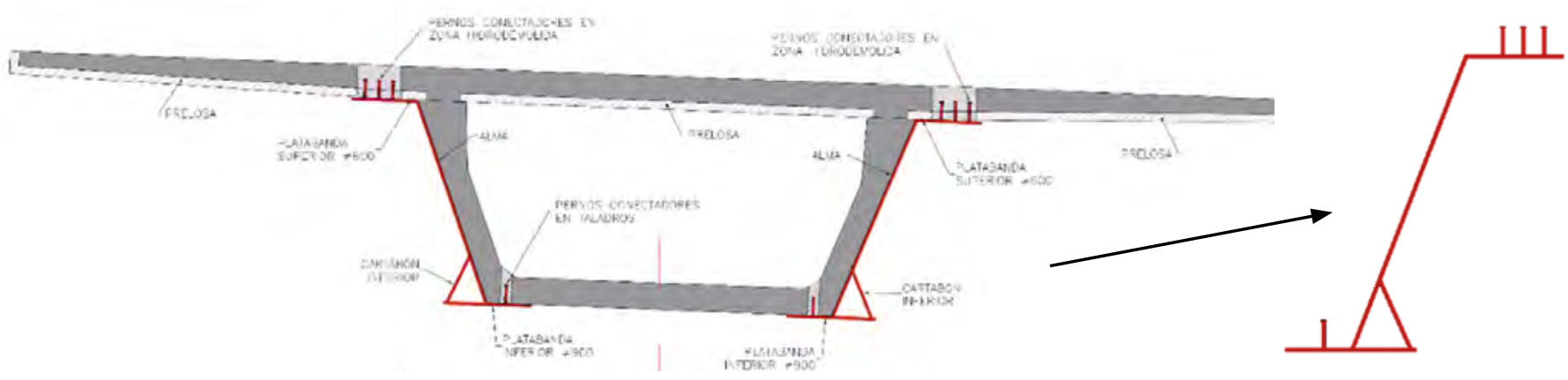

Figura 17. Sección transversal tipo de la solución propuesta y detalle de sección tipo del refuerzo metálico.

complementario que permitiera asegurar el adecuado comportamiento del tablero en el tiempo. Las principales patologías detectadas se correspondian con:

- Fisuración de las almas de las vigas de hormigón pretensado. Todas las vigas presentaban series de fisuras longitudinales corridas a lo largo de la estructura. Dichas fisuras estaban instrumentadas, por lo que se podía comprobar que se trataba de fisuras vivas.

- Apertura de juntas entre vigas. Los empalmes entre las vigas cajón consecutivas se materializaban mediante el tradicional sistema de unión con barras de pretensado. Durante las diferentes inspecciones realizadas se pudo verificar cómo las juntas del vano central se estaban abriendo con el paso de los años.

- Evolución de la flecha en el centro de vano del tramo central, que se encontraba cerca de afectar a la funcionalidad de la estructura.

Complementando los trabajos de análisis teórico de la estructura, se llevó a cabo una campaña de auscultación in situ de la misma, realizando calas para identificación de armados, extrayendo testigos del hormigón, análisis químicos, etc. El estado y el comportamiento resistente de las estructuras resultaban, a raíz de las patologías indicadas, inciertos.

Su situación, unida a la importante evolución de las deformaciones del tablero, que no se encontraban estabilizadas, y a la apertura de las juntas pretensadas del centro de vano del tablero, llevaron a tomar la decisión del refuerzo estructural del puente.

Dado que los principales daños que presenta la estructura se manifiestan en toda su extensión, y sin formar un patrón identificable, se consideró que la solución de reparación del puente tenía que ser global y definitiva, de forma que se pudiese restablecer y garantizar el nivel de seguridad y fiabilidad de la estructura conforme a la normativa vigente, descartando buscar soluciones de refuerzo local.

Dentro del estudio de las posibles alternativas de reparación se analizaron soluciones con hormigón, que fueron descartadas, ya que, o bien requerían el saneo y refuerzo de las zonas dañadas, actuación que debía hacerse por pequeños bataches y que no garantizaba el completo restablecimiento de la capacidad resistente del puente, o bien eran refuerzos muy complejos, difíciles de ejecutar y con una importante modificación de la estética de la obra original, así como incremento de peso.
La demolición también fue una opción estudiada y descartada por diferentes motivos, como son las importantes afecciones al tráfico de la A-66, los amplios plazos de ejecución, y el importante impacto ambiental (no solo por los residuos generados en la demolición sino por la necesidad de invadir el cauce del río Duero para la ejecución de la nueva estructura). Junto a todos los anteriores se encontraba la obligación de los ingenieros estructurales por conservar el patrimonio existente y ponerlo en valor, máxime teniendo en cuenta que se trata de un puente singular, y de gran belleza.

Descartadas las opciones citadas, se exploraron las alternativas que el metal podía aportar para la reparación, pensando fundamentalmente en la flexibilidad, facilidad de ejecución y respeto formal que este material podía aportar.

Conforme a dicho planteamiento, se consideró como posible solución estructural del tablero disponer unas vigas metálicas adosadas a las actuales vigas de hormigón, así como a la losa del puente, haciendo la sección colaborante y convirtiendo el actual tablero de hormigón pretensado en un puente mixto de doble acción mixta con capacidad de resistir tanto las actuales cargas permanentes como las sobrecargas de uso (figura 17). La interfase acero-hormigón se rellenó mediante una lechada rica en cemento con objeto de evitar la presencia de huecos y garantizar la durabilidad de la estructura.

Entre los aspectos que llevaron a la elección de esta solución se encontraban:

- Permitía conservar íntegramente la estructura existente evitando la demolición de los elementos afectados.

- Se aprovechaba la capacidad resistente de la losa superior y la tabla inferior del cajón que se encontraban en buen estado de conservación.

- Optimización del uso de los materiales, disponiendo únicamente estructura de refuerzo en las zonas dañadas (almas del cajón).

- Posibilidad de reutilizar la subestructura del puente sin más que hacer una mínima adaptación geométrica para realizar la correcta transmisión de las cargas del refuerzo metálico a la propia subestructura. (figura 18).

- La solución mostraba un gran respeto por la estética (forma) original de la obra, ya que prácticamente se limita a disponer de un forro metálico exterior. Si bien en un primer momento se planteó la posibilidad de usar acero pintado en color gris, manteniendo el aspecto inicial de la estructura, finalmente se optó por el uso de acero autopatinable, de forma que se redujeran sus necesidades de conservación futuras. 


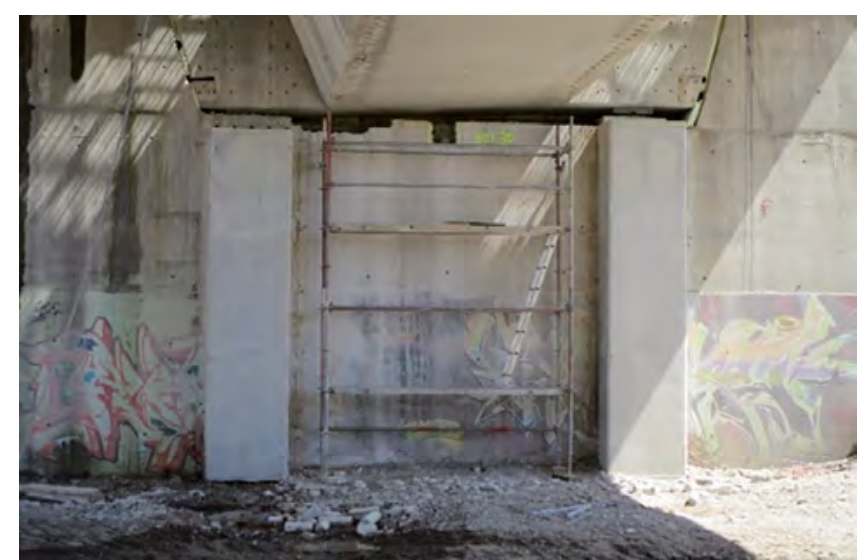

Figura 18. Vista de los recrecidos frontales en los estribos.

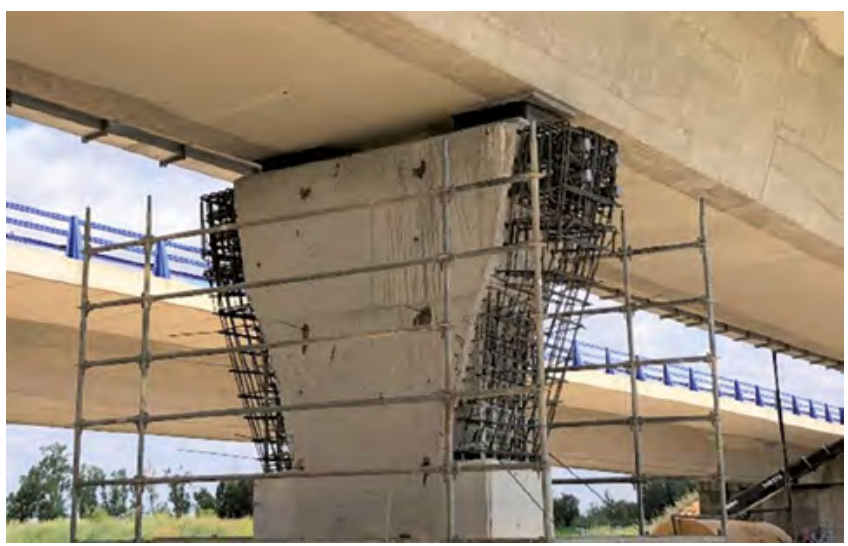

Figura 19. Vista de los recrecidos laterales en las pilas convencionales.

- Aunque finalmente, aprovechando épocas valle de IMD (Intensidad Media Diaria) de la autovía se optó por realizar el corte total del viaducto, la solución proyectada permitía ejecutar la solución manteniendo un carril de circulación, minimizando las afecciones al tráfico.

- Todos los trabajos se podían ejecutar desde la propia plataforma o desde tierra, y en ningún caso era necesario invadir el cauce del río Duero.

\subsection{Adaptación de la subestructura}

Los primeros trabajos que fue necesario acometer fueron la adaptación de la subestructura para recibir los esfuerzos transmitidos por la nueva estructura mixta.

En el caso de los estribos, se tuvo que adelantar el eje de apoyos existentes para poder apoyar la nueva estructura metálica.

El reducido espacio existente en los estribos no permitía la nueva disposición, por lo que se ejecutaron dos recrecidos frontales de los muros de estribo, debidamente conectados a los mismos para poder disponer los nuevos aparatos de apoyo.

En el caso de las pilas convencionales, debido a la geometría del refuerzo metálico, se desplazó lateralmente hacia el exterior la posición de ambos apoyos para permitir que las almas metálicas apoyasen sobre los mismos. Por este motivo, se recrecieron lateralmente las pilas.

Dicho recrecido consistió en la hidrodemolición parcial de las mismas en sus laterales y la ejecución de un recrecido de hormigón armado conectado a la pila existente. Asimismo, se dispusieron barras de pretensar en la dirección transversal de la pila para soportar las tracciones de desvío generadas por la nueva posición de los aparatos de apoyo (figura 19).

\subsection{Vigas metálicas: montaje, ensamblaje de tramos, cone- xión al cajón existente}

Como se ha mencionado, la solución de refuerzo diseñada consiste en disponer por el exterior del cajón de hormigón existente sendas almas metálicas que permiten realizar un refuerzo integral de las mismas, y que permite configurar una sección mixta de doble acción mixta conectándolas a la losa superior e inferior. La nueva sección resistente, formada por las almas metálicas y las losas de hormigón, es capaz de resistir tanto el peso propio de la estructura como las sobrecargas indicadas en la normativa vigente, siendo plenamente funcional.

Los principales retos de la obra eran conseguir fabricar una estructura metálica que se adaptase a la estructura original, curva y con deformaciones diferentes en cada vano, dar continuidad a las diferentes dovelas y conectarlas a la estructura existente sin dañar los elementos resistentes.

El montaje del refuerzo metálico comenzó con la colocación de las dovelas de estribos y pilas. Dichas dovelas, de dimensiones reducidas, eran las que debían apoyar sobre los nuevos aparatos de apoyo para realizar la transmisión de cargas del tramo metálico a la subestructura (figura 20).

Para poder colocar las dovelas fue necesario liberar espacio retirando los apoyos existentes. Para ello se realizó un levantamiento del tablero usando gatos hidráulicos sincronizados mediante una central electrónica. Una vez apeado el tablero, se procedió a la retirada de los apoyos existentes, empleando corte con hilo en el caso de los apoyos tipo pot o con medios convencionales en el caso de los apoyos de neopreno zunchado.

Las dovelas cero se montaron por semi-mitades (una por lateral) desde tierra con una única grúa y, posteriormente en obra se ejecutaron las soldaduras de unión de la platabanda inferior de ambos laterales.

En el caso de las dovelas de estribo, estas, iban a su vez vinculadas a la riostra de hormigón existente mediante varillas roscadas ancladas con resina a dicho elemento (figura 21).

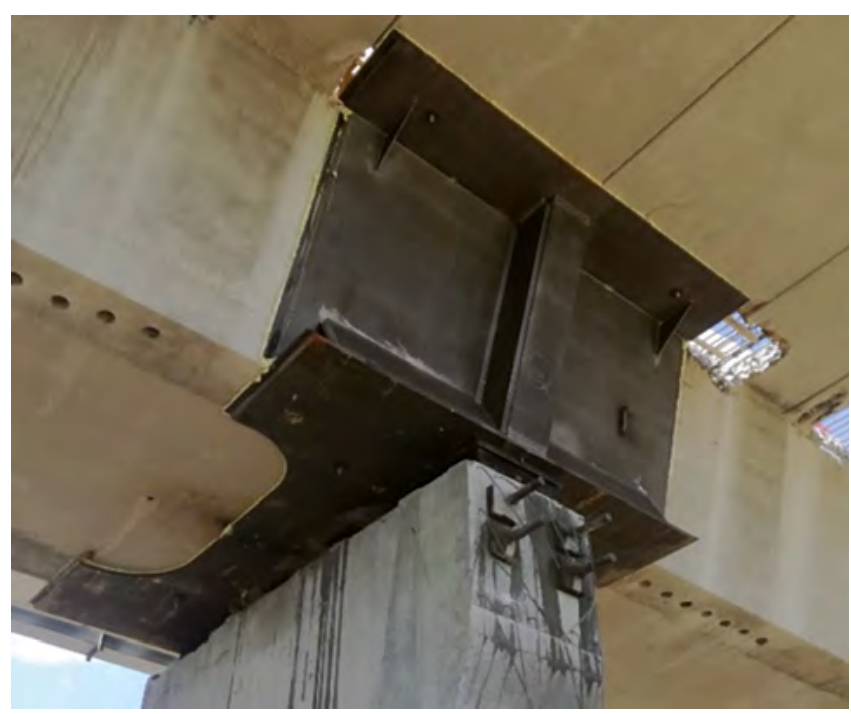

Figura 20. Montaje de dovelas de pila. 


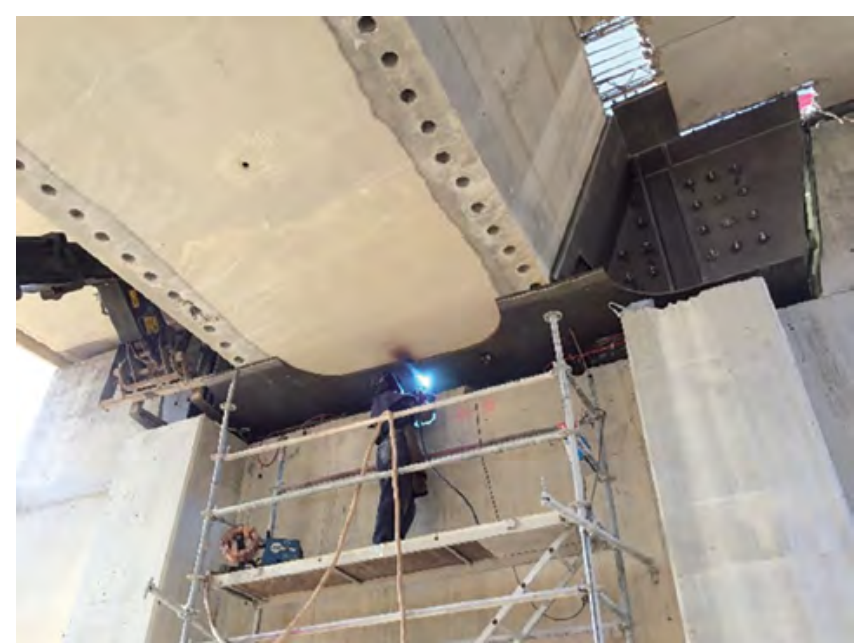

Figura 21. Montaje de dovelas de estribo y ejecución de soldadura de conexión in situ.

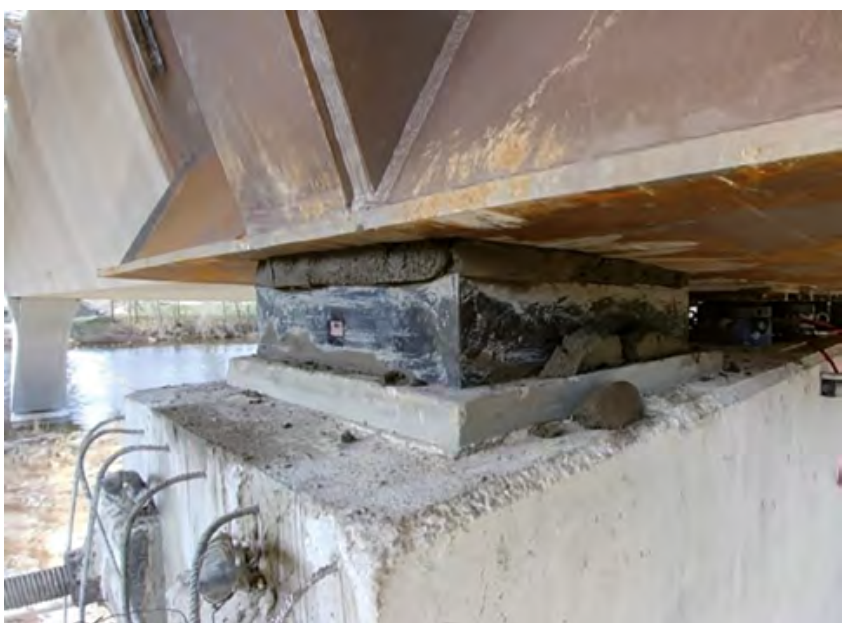

Figura 22. Descenso del tablero sobre los nuevos aparatos de apoyo.

Una vez montadas todas las dovelas de estribo y pilas se descendió el tablero sobre los nuevos aparatos de apoyo, de neopreno zunchado (figura 22), instalados en los recrecidos mencionados.

Una vez instaladas las dovelas de estribos y pilas y garantizado el correcto apoyo de la nueva estructura metálica sobre los neoprenos, se procedió al montaje de las dovelas de vano.

Las dovelas fueron fabricadas en taller y tenían una longitud tal que cubría todo el vano, a excepción del vano sobre el río y los vanos adyacentes donde debido a la limitación de carga de las grúas los vanos estaban formados por dos dovelas en cada lateral (figura 23). Para asegurar que las vigas metálicas se ajustaban al tablero existente se realizó un modelo geométrico 3D del tablero mediante el uso de un laser scanner. Dicho modelo permitió al taller fabricar las dovelas de acuerdo a la geometría existente, dotándolas de la curvatura necesaria para adaptarse a la geometría existente (figura 24), manteniéndose dentro de las tolerancias de ejecución.

Para materializar el comportamiento mixto a sección completa resulta necesario, como se ha explicado, conectar las vigas metálicas a la estructura de hormigón existente. La conexión de la platabanda superior metálica a la losa superior se resolvió mediante pernos conectadores. Con este fin, se ejecutaron en el voladizo una serie de "ventanas" mediante la hidrodemolición de todo el canto de la losa que permitían alojar los pernos conectadores. Las ventanas tenían unas dimensiones de unos 2,00 m según el eje del puente y una anchura de $0,50 \mathrm{~m}$ en la dirección transversal. La separación entre ventanas era de unos $0,80 \mathrm{~m}$ lo que permitía que la disposición de pernos fuese constante a lo largo de todo el vano (figura 25).

La conexión de la platabanda inferior con la tabla inferior de las vigas prefabricadas se realizó nuevamente con pernos, pero, en este caso, se ejecutaron taladros con corona de diamante en la viga para poder alojarlos. Para poder ejecutar los taladros con seguridad, se realizó un replanteo preciso de las vainas del pretensado longitudinal para garantizar que no se dañaban (figura 26).

Dada la dificultad para asegurar que los pernos pudiesen ser soldados en taller en la posición correcta debido a las reducidas tolerancias de montaje, se optó por soldar los pernos de la platabanda inferior in situ mediante equipo de soldadura de pernos con pistola.

Una vez ejecutadas las ventanas en la losa superior y los taladros en la losa inferior para alojar los pernos se estaba en disposición de proceder al montaje del refuerzo metálico.

Al tratarse de un refuerzo de un puente existente, no resultó posible el montaje convencional de las vigas metálicas directamente con grúa. Por ello, hubo que diseñar unos útiles especiales que permitiesen coger las dovelas y desplazarlas por debajo del voladizo hasta su posición final (figura 27, 28 y 29).

Una vez situadas en la posición definitiva y ajustadas a la estructura existente, las dovelas se fijaron al tablero de hormigón mediante anclajes provisionales de forma que se pudiesen liberar los útiles de montaje.

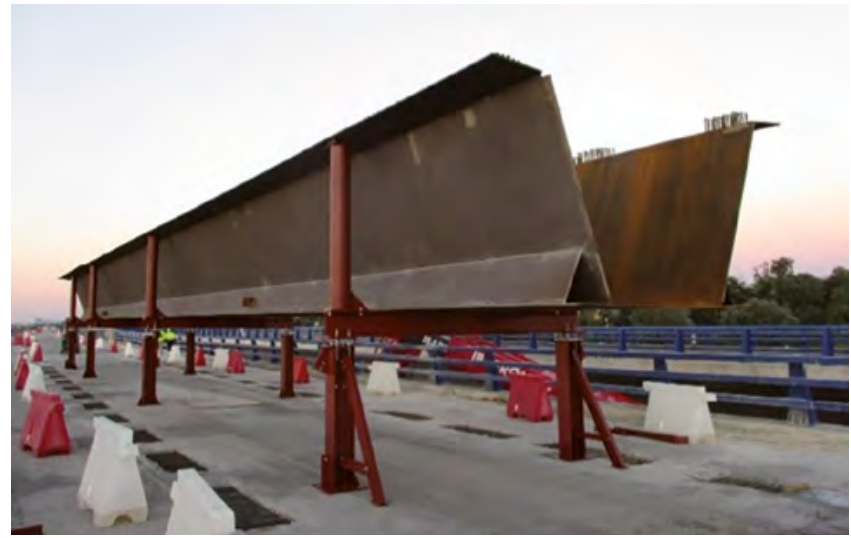

Figura 23. Dovelas sobre la plataforma listas para su montaje.

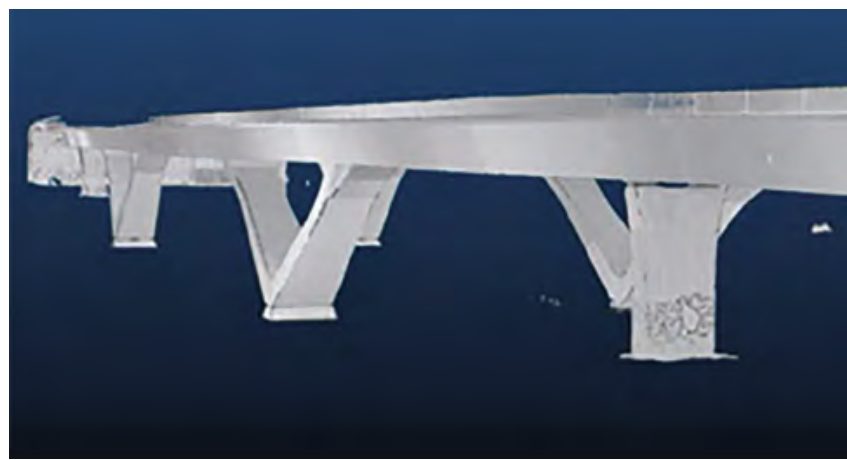

Figura 24. Modelo geométrico 3D del puente existente. 


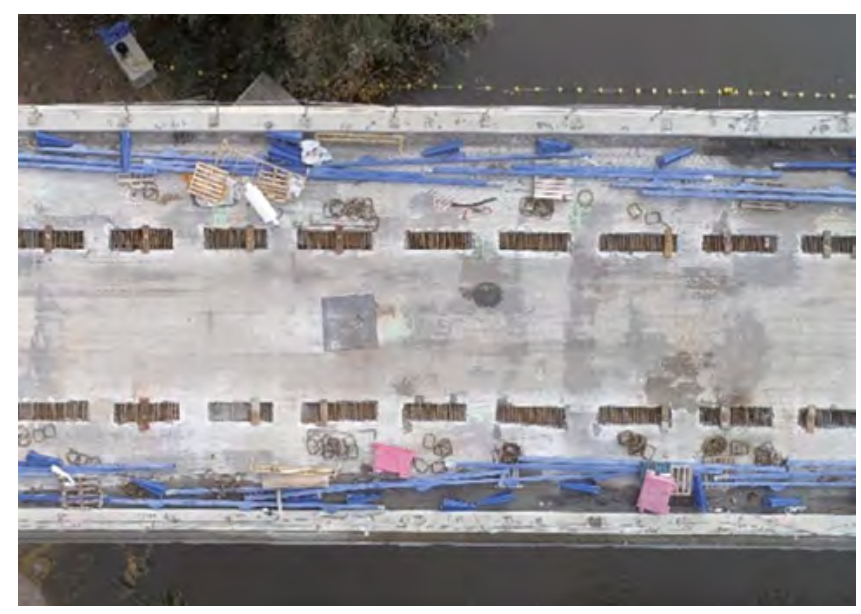

Figura 25. Vista en planta de la estructura con las ventanas ejecutadas en los voladizos para alojar los pernos conectadores de la platabanda superior.

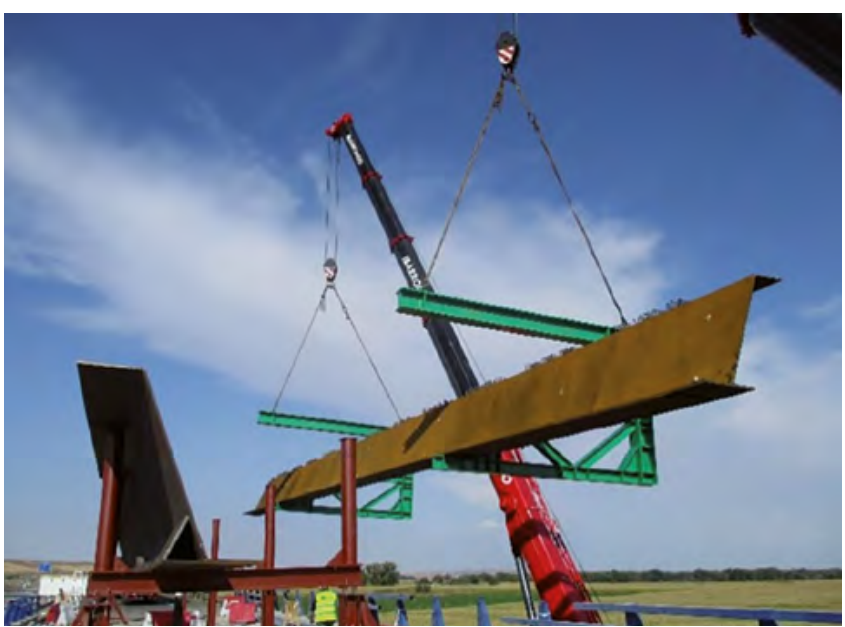

Figura 27. Dovela sobre los útiles de izado diseñados para el montaje.

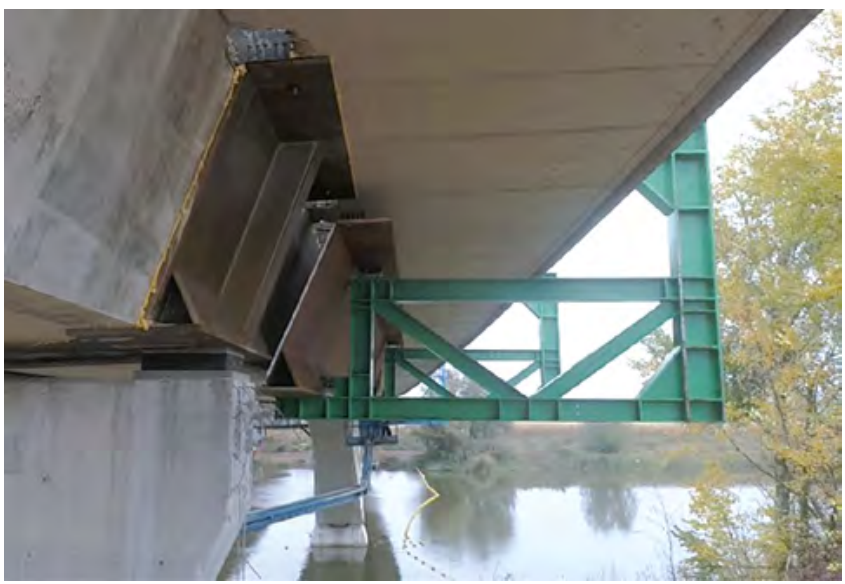

Figura 29. Montaje de dovelas.

Situada la dovela en posición, se procedío a soldar ambos extremos a las dovelas cero que habían sido previamente montadas y ya descansaban sobre los nuevos aparatos de apoyo.

Los pernos de la platabanda inferior tenían que ser soldados in situ desde el interior del cajón, como se ha indicado. Una vez soldados, los taladros se rellenaban con un grout sin retracción.

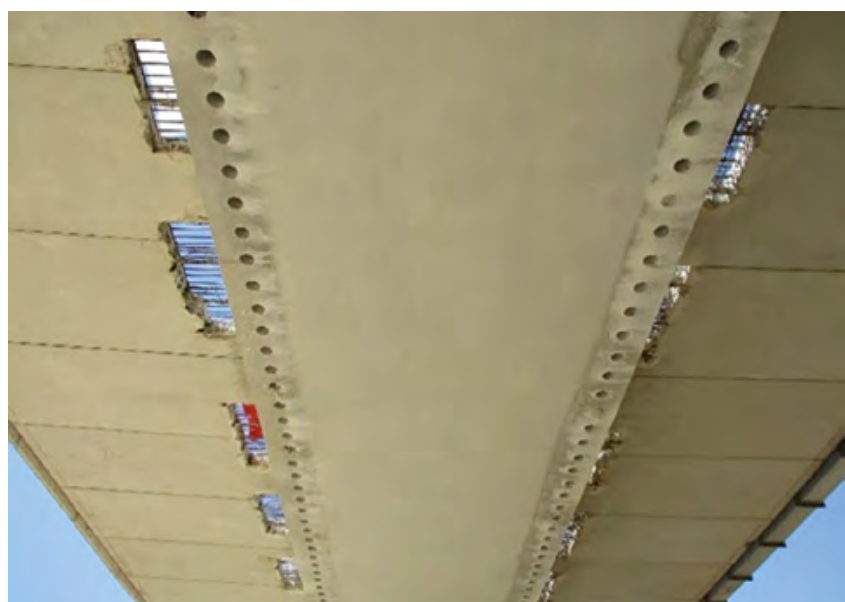

Figura 26. Vista inferior del tablero con las ventanas en el voladizo y los taladros en la losa inferior para alojar los pernos de conexión.

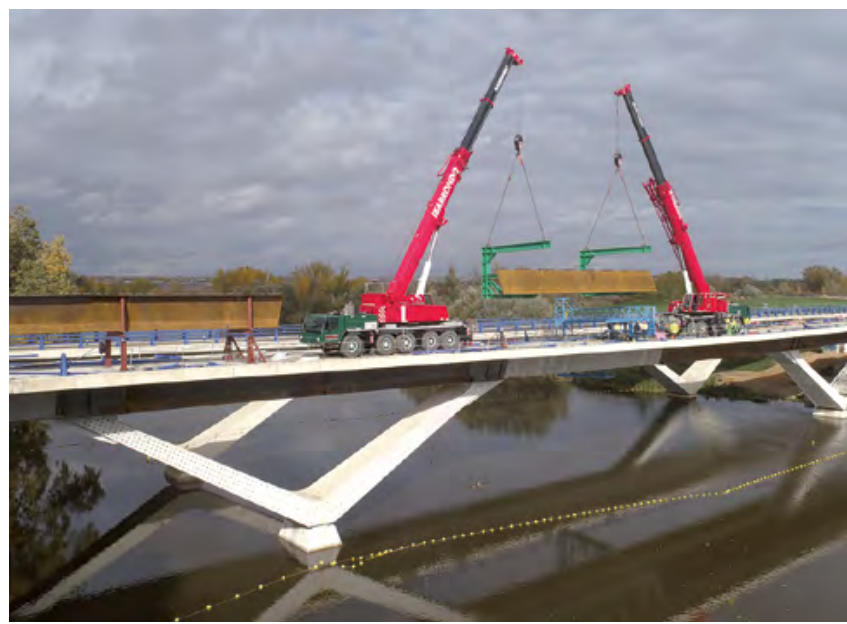

Figura 28. Montaje de dovelas.

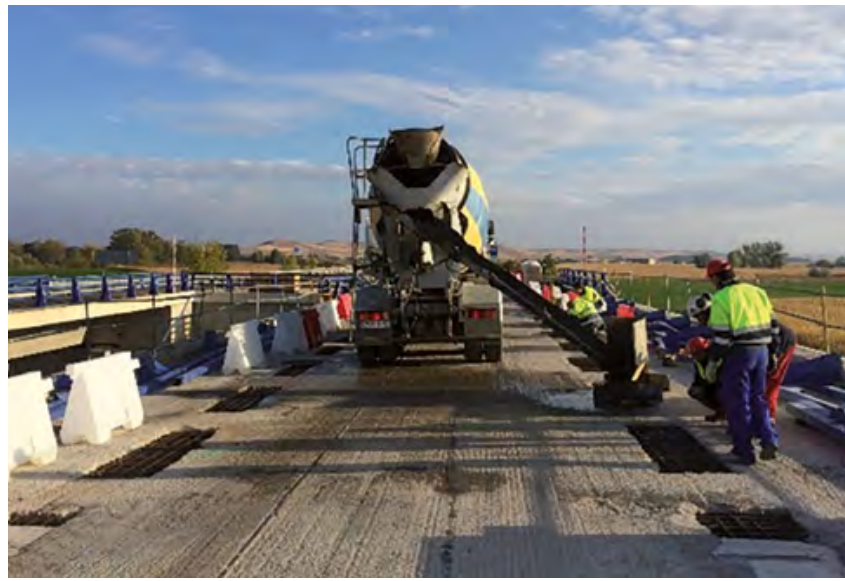

Figura 30. Hormigonado de las ventanas ejecutadas en los voladizos para alojar la conexión superior.

A continuación, se rellenó la interfase alma de hormigón - alma metálica con una lechada de cemento que, si bien no tenían un fin estructural en sí mismo, aseguraba que no entrase agua u otro tipo de elementos, garantizando la durabilidad de la estructura.

Finalmente se procedió al hormigonado de las ventanas de la losa superior con los pernos conectadores (figura 30). 


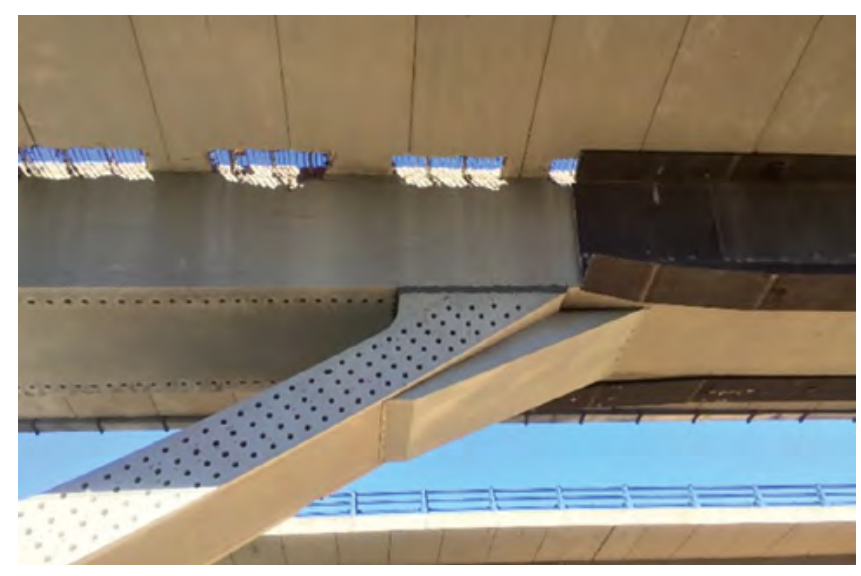

Figura 31. Taladros en la pila en "V" para alojar los pernos.

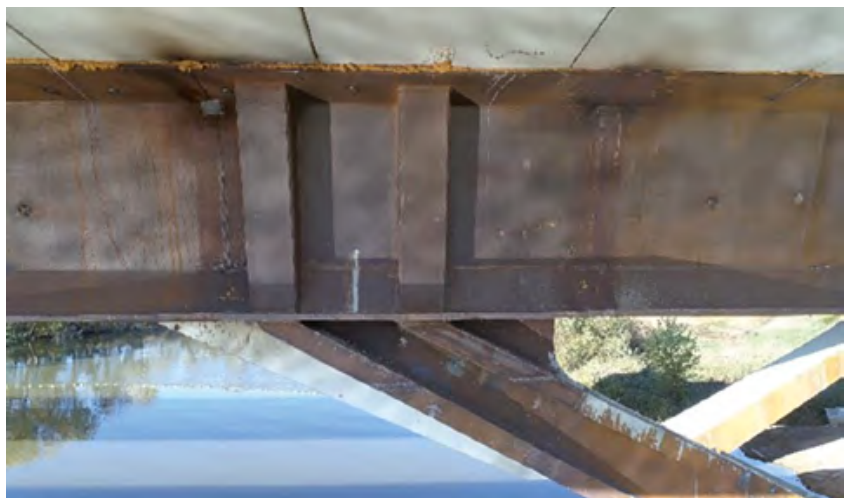

Figura 33. Vista de las pilas en V.

\subsection{Montaje de nudo dintel-pilas en "V"}

El viaducto cuenta con dos pilas en forma de "V" conectadas monolíticamente con el tablero. En estas pilas no era posible realizar el procedimiento de transmisión de cargas del tablero a la subestructura según el procedimiento diseñado para las pilas convencionales. La solución propuesta consistió en transmitir la carga del tablero a la pila de hormigón por rasante, disponiendo una chapa adosada a las pilas en "V" y conectándola con pernos. De esta manera, se garantizaba la transferencia de carga, y se realizaba un refuerzo de la sección.

Para alojar los pernos se realizaron taladros a lo largo de toda la pila. Posteriormente, con el uso de un dron se replantearon todos los agujeros para poder soldar en taller los pernos con la precisión requerida, dada la reducida tolerancia de montaje (figura 31).

El forro metálico de las pilas en "V" se montó con los mismos útiles utilizados para el montaje de las dovelas de vano. En este caso se soldaron unos bastidores a las piezas con el fin de rigidizarlas durante el montaje y de dotar a la pieza de un punto para el izado (figura 32).

Una vez en posición se soldó la chapa principal a la platabanda inferior de la dovela cero de dichas pilas. Asimismo, se dio continuidad a los rigidizadores de las dovelas cero a lo largo de dichas piezas (figuras 33 y 34).

Por último, se rellenaron todos los agujeros de los pernos y la interfase entre la pila de hormigón y la chapa metálica con un mortero fluido.

La figura 35 muestra el estado final del puente en el que, como se puede observar, se ha conseguido mantener la estética

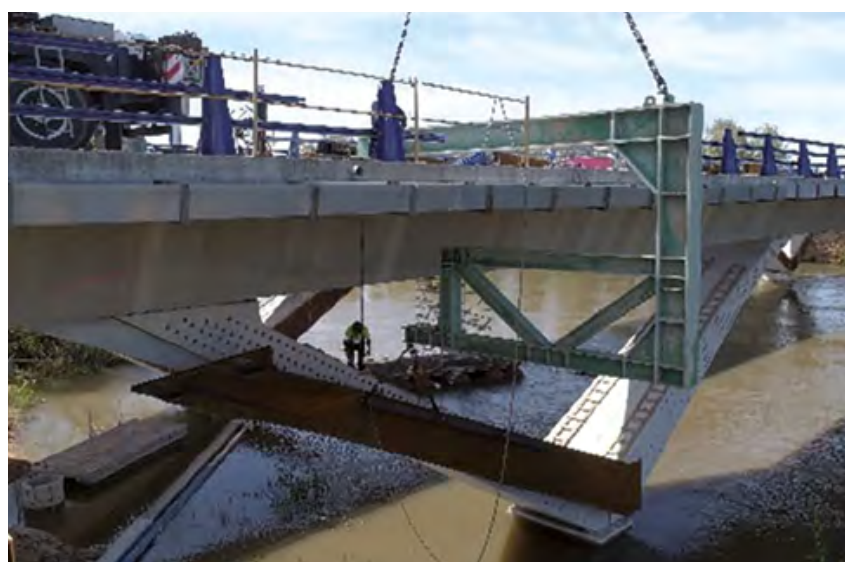

Figura 32. Montaje del forro metálico en pilas en V.
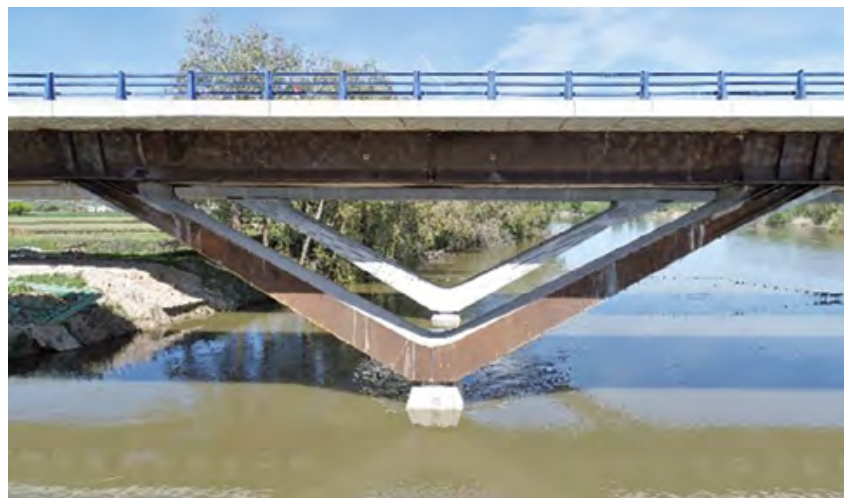

Figura 34. Vista del nudo de las pilas en V.

formal de la estructura, siendo este uno de los objetivos fundamentales de la intervención.

\subsection{Relación de participantes}

- Propiedad: Ministerio de Transportes, Movilidad y Agenda Urbana. Dirección General de Carreteras. Subdirección General de Conservación.

- Dirección de obra: Demarcación de Carreteras del Estado en Castilla y León Occidental. Unidad de Carreteras del Estado en Zamora.

- Director de las obras: Javier Largo Maeso (Jefe de la Unidad de Carreteras del Estado en Zamora)

- Constructora: COLLOSA:

Eduardo Vara Pazos (Director de conservación de carreteras)

Álvaro García Martín (Jefe de obra)

- Inspección, diagnóstico, diseño de solución de reparación y asistencia técnica especializada: IDEAM S.A.:

Francisco Millanes Mato

Luis Matute Rubio

Ignacio Pulido Sánchez

Enrique Bordó Bujalance

Santiago Salas Fernández-Polanco

Carlos Jiménez Solanas

Fu Lei Zhou

Alberto Marino Tostón 


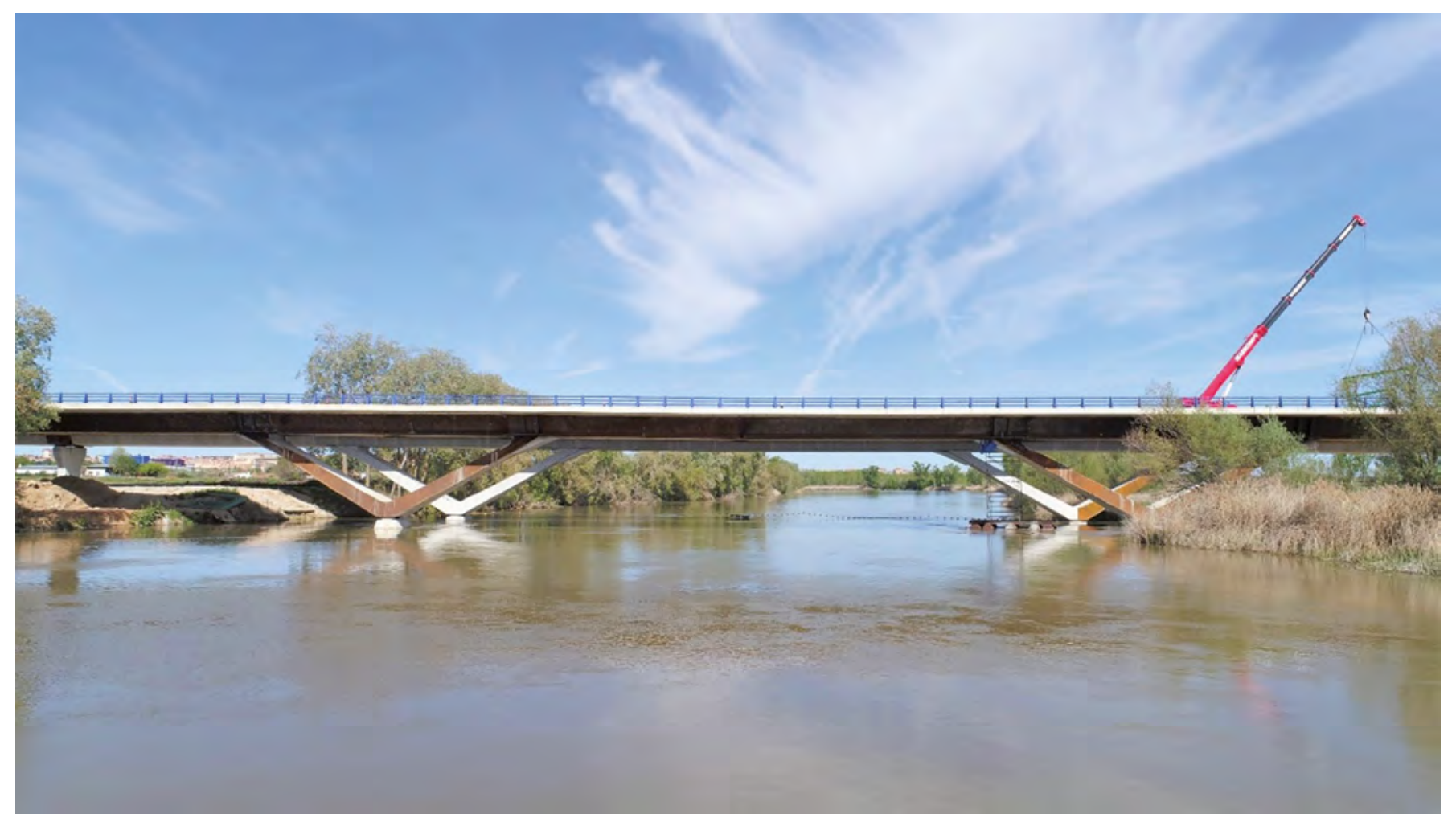

Figura 35. Vista del nuevo puente mixto tras las obras de reparación.

\section{Referencias}

[1] Martínez J. (1995) Ampliación de las luces de 15 pasos superiores continuos postesados, para conseguir el ensanchamiento a seis carriles de la autopista A-7 Barcelona-La Junquera. Tramo Hostalric-Maçanet. Hormigón y Acero, 46(196):133-146.

[2] Martinez J., Ladron de Guevara G. (2003) Ampliaciones de luces de pasos superiores de autopistas existentes. Solucion aplicada en la autopista A-7 (by-pass) Valencia.", II Congreso ACHE.

[3] Martínez J., Ceriani L. (2008) "Estación de Sants en Barcelona - grandes dinteles de apeo para eliminación de soportes entre vías". IV Congreso ACHE. 